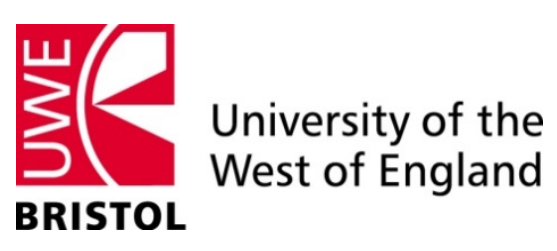

Faculty of Business and Law

\title{
Modelling the sectoral allocation of labour in open economy models
}

\author{
Laura Povoledo \\ Department of Accounting, Economics and Finance, \\ University of the West of England, Bristol, UK
}

Economics Working Paper Series

1312 


\title{
Modelling the Sectoral Allocation of Labour in Open Economy
} Models

\author{
Laura Povoledo* \\ University of the West of England ${ }^{\dagger}$
}

November 2016

\begin{abstract}
Indivisible labour is not the only type of nonconvexity affecting labour supply decisions. Another type of nonconvexity arises in economies with sectors whenever individuals can work in only one sector at a time. I introduce this restriction into an open economy model with a tradeable and a nontradeable sector, and I use lotteries to convexify the consumption possibilities set. This approach implies that the aggregate elasticity of labour supply becomes infinite. I compare the performance of the model with an analogous model in which the labour supply elasticity is finite. I find that there is a disconnect between the response of wages to monetary shocks and the open economy variables. The labour supply elasticity plays a more important role in the transmission of technology and government expenditure shocks to the real exchange rate and the terms of trade.
\end{abstract}

JEL classification: E24; E32; F41.

Keywords: Tradeable and nontradeable sectors; International business cycles; Labour supply elasticity.

\footnotetext{
*I am grateful to Parantap Basu, Iris Biefang-Frisancho Mariscal, Peter Howells, Stephen McKnight, participants at the MMF 2011, EEFS 2012, Birmingham Macroeconomics and Econometrics conferences, the editor and two anonymous referees for helpful comments. Any errors or shortcomings are my sole responsibility.

${ }^{\dagger}$ Coldharbour Lane, Bristol BS16 1QY (UK). Tel: 004411732 83454. Email: Laura.Povoledo@uwe.ac.uk.
} 


\section{Introduction}

This paper studies the performance of a two-country model with tradeable and nontradeable sectors in which individuals cannot supply their labour services to both sectors at the same time. Accounting for the non-convexity arising from this restriction is important for two reasons. First, the data show that most people do not or cannot hold two jobs at the same time. ${ }^{1}$ Secondly, macroeconomists have developed models with non-convexities which reconcile low individual labour supply elasticities with the observed large fluctuations of aggregate hours over the business cycle. In my model, the aggregate labour supply elasticity is infinite, as in a classic indivisible labour model. I find that there is a "disconnect" between the open economy variables and the elasticity of labour supply. Therefore the motivation of the paper is twofold: (1) to analyse one type of nonconvexity which is relevant to open economy models with tradeable and nontradeable sectors; and (2) to investigate the role played by the labour supply elasticity in open economy models.

This paper contributes to the literature by examining the implications of a non-standard assumption regarding the allocation of hours worked between sectors. Many open economy models have two sectors, one producing internationally traded goods and one producing nontradeable goods, so they must also specify how individuals choose to allocate their labour time between the two sectors. The standard assumption is that only the sum of hours worked enters the utility function. As a result, the representative agent is completely indifferent between, for example, working 20 hours a week in a tradeable sector firm plus 20 hours in a nontradeable sector firm, and working 40 hours a week in only one of the two firms. Instead, I consider an economy in which individual choices are restricted, either work in one sector or the other, so the consumption possibilities set is non-convex. This environment was first introduced by Rogerson (1988b). Like him, I assume employment lotteries with complete markets and I show that the utility function features both the intensive (hours) and the extensive (participation rates) margins of labour supply. However, these preferences imply that all the adjustment in the labour supply occurs through the extensive, not the intensive, margin, and the Frisch elasticity of the labour supply is infinite.

As it is well known, the observed large fluctuations in aggregate hours imply that the aggregate labour supply elasticity must be large (Prescott 2005). Moreover, a large labour supply elasticity is

\footnotetext{
${ }^{1}$ In 2013 the multiple jobholders as a percent of employed people in the US were just 4.9\% (Source: Bureau of Labor Statistics).
} 
important for monetary shocks to have persistent effects on output (Chari, Kehoe and McGrattan 2000). However, estimated elasticities from microeconometric studies are well below the calibrated values in macroeconomic models. Seminal work by Hansen (1985) and Rogerson (1988a) showed that these opposing facts can be reconciled by assuming that individual agents are only allowed to make the choice as to whether to be employed or not, but cannot adjust the number of hours worked. In this environment, the elasticity of the aggregate labour supply is infinite. Critics of Rogerson's aggregation consider it to be at odds with microeconomic observations, because it relies on employment lotteries with complete markets. However, recently Ljungqvist and Sargent (2005, 2011), and Rogerson and Wallenius (2009) have explored an alternative 'time-averaging' aggregation, according to which individuals face a $\{0,1\}$ employment choice in each period and choose what fraction of their lifetime to work. So far, this debate has not influenced the open economy literature, despite the fact that a special kind of labour indivisibility arises quite naturally in economies with sectors (Rogerson 1988b).

Nevertheless, several contributions have uncovered a number of open economy results which depend on the labour supply elasticity. Basu and Kollmann (2013) and Kollmann (2010) show that a high labour supply elasticity is necessary to ensure that the real exchange rate depreciates after an increase in government expenditure, consistently with the empirical evidence. Using a twosector dependent economy model, Morshed and Turnovsky (2011) show that the elasticity of labour supply affects the speed of convergence of the real exchange rate to its long-run equilibrium value. Corsetti, Martin and Pesenti (2007) analyse the reallocation of endogenous product varieties to the most productive country following a shock. They find that this reallocation can be considerable, but only if the labour supply elasticity is so high that relative wages are not affected by the shock. In contrast to these contributions, I do not focus on a specific effect or statistics, but instead I investigate the impact of the labour supply elasticity on the second-order moments of several variables. I consider both demand (money and government expenditure) and supply-type (productivity) shocks, and I show that the consequences of varying the labour supply elasticity are dependent on the pricing assumption.

As in Obstfeld and Rogoff (1995), my model features monopolistic competition and price rigidity. An important issue in this literature is the choice of currency of invoicing. This choice is important because in a two-country, two-currency world it is possible to model price rigidity in different ways. 
One way, for example, is to assume that the law of one price holds and that prices are sticky in the currency of the producer (producer currency pricing or PCP). This assumption is made, among others, by Obstfeld and Rogoff (1995, 2000, 2007), Corsetti and Pesenti (2001), Galí and Monacelli (2005), and Benigno (2009). Another possibility is to assume that prices are sticky in the currency of the destination market (local currency pricing or LCP). This assumption is made, for example, by Betts and Devereux (1996, 2000), Kollmann (2001), Chari, Kehoe and McGrattan (2002), Benigno and Thoenissen (2003), and Sutherland (2005). To date, the choice of pricing assumption and the degree of exchange rate pass-through into import prices are still open questions in the literature, therefore I check the robustness of the results to the choice of currency of invoicing.

Since the Frisch elasticity of labour supply cannot be calibrated freely, I compare the performance of the infinite elasticity model with an analogous model in which individuals supply their labour services to both sectors at the same time, and the labour supply elasticity is finite. I find that the infinite labour supply elasticity dampens the response of wages and prices to monetary shocks, but the decreased volatility of wages and prices has almost no effect on the volatility of the terms of trade, and no effect at all on the volatility of real and nominal net exports. Therefore, there is a disconnect between the open economy variables and the response of wages. Additionally, the relationship between the speed of price adjustment (or the volatility of inflation) and the volatility of the nominal exchange rate is weak. On the other hand, the Frisch elasticity of labour supply plays an important role in the transmission of non-monetary shocks. The response of the terms of trade and the real exchange rate to technology and government expenditure shocks is stronger if the Frisch elasticity is relatively lower.

The remainder of the paper is as follows. Section 2 illustrates the model, and Section 3 the alternative assumption that individuals supply labour contemporaneously to both sectors. The calibration of the model is described in Section 4. Sections 5, 6 and 7 explain the results, and Section 8 concludes.

\section{The model}

The model includes features such as Calvo-style price rigidity, nontradeable goods and home bias in consumption. The elasticity of exchange rate pass-through is a free parameter of the model, 
which nests both PCP and LCP as special cases. Throughout Sections 2 to 6 I assume PCP, and I consider alternative pricing mechanisms in Section 7.

The world economy consists of two countries, Home and Foreign. Both countries have two sectors, and in each sector there exists a continuum of monopolistic firms, each of them producing a single differentiated product, or brand. The notation is as follows. The firms and the goods they produce are indexed by $f_{T H} \in[0,1]$ for the Home tradeable sector and $f_{N} \in[0,1]$ for the Home nontradeable sector. In the Foreign country, they are indexed by $f_{T F}^{*} \in[0,1]$ and $f_{N}^{*} \in[0,1]$ respectively. All Foreign variables and indexes are denoted with stars. Prices of individual varieties are denoted with lower cases, aggregate prices with upper cases. Steady state variables have a zero time index.

\section{Firms}

Each firm has a fixed probability of changing its prices at date $t$. I follow the approach of Corsetti and Pesenti (2005), and assume that the local currency prices of exports of Home and Foreign tradeable varieties $f_{T H}$ and $f_{T F}^{*}$ are given, respectively, by:

$$
p_{T H, t}^{*}\left(f_{T H}\right)=\frac{\widetilde{p}_{T H, t}\left(f_{T H}\right)}{e_{t}^{\zeta^{*}}}, \quad p_{T F, t}\left(f_{T F}^{*}\right)=e_{t}^{\zeta} \widetilde{p}_{T F, t}^{*}\left(f_{T F}^{*}\right)
$$

where $e$ is the nominal exchange rate (price of the Foreign currency in terms of the Home currency), $\zeta$ and $\zeta^{*}$ are the pass-through elasticities into export prices, constant by assumption, and $\widetilde{p}_{T H}\left(f_{T H}\right)$ and $\widetilde{p}_{T F}^{*}\left(f_{T F}^{*}\right)$ are predetermined components that are not adjusted to variations in the exchange rate during period $t$. Thus, if both $\zeta$ and $\zeta^{*}$ are equal to one the exchange rate pass-through is complete, and if they are equal to zero the pass-through is zero.

Tradeable goods firms in both countries set two different prices, one for the Home market and one for the Foreign market. For example, a Home tradeable sector firm $f_{T H}$ chooses the price $p_{T H, t}\left(f_{T H}\right)$ of domestic sales, and the predetermined component $\widetilde{p}_{T H, t}\left(f_{T H}\right)$ of the export price, by maximising the present discounted value of profits: 


$$
E_{t} \sum_{j=0}^{\infty}(\varphi \beta)^{j} Q_{t, t+j}\left[\begin{array}{c}
\frac{p_{T H, t}\left(f_{T H}\right)}{P_{t+j}} \cdot y_{T H, t+j \mid t}\left(f_{T H}\right) \\
+e_{t+j} \frac{p_{T H, t+j}^{*}\left(f_{T H}\right)}{P_{t+j}} y_{T H, t+j \mid t}^{*}\left(f_{T H}\right) \\
-\frac{W_{T H, t+j}}{P_{t+j}} \cdot \widetilde{h}_{T H, t+j \mid t}\left(f_{T H}\right)
\end{array}\right]
$$

subject to:

$$
\begin{aligned}
y_{T H, t+j \mid t}\left(f_{T H}\right) & =\left(\frac{p_{T H, t}\left(f_{T H}\right)}{P_{T H, t+j}}\right)^{-\eta} C_{T H, t+j}, \\
y_{T H, t+j \mid t}^{*}\left(f_{T H}\right) & =\left(\frac{p_{T H, t+j \mid t}^{*}\left(f_{T H}\right)}{P_{T H, t+j}^{*}}\right)^{-\eta} C_{T H, t+j}^{*}, \\
p_{T H, t+j \mid t}^{*}\left(f_{T H}\right) & =\tilde{p}_{T H, t}\left(f_{T H}\right) e_{t+j}^{-\zeta^{*}},
\end{aligned}
$$

where $Q_{t, t+j}=\frac{u^{\prime}\left(C_{t+j}\right)}{u^{\prime}\left(C_{t}\right)}, \beta$ is the discount factor, and $(\varphi)^{j}$ is the probability that $p_{T H, t}\left(f_{T H}\right)$ and $\widetilde{p}_{T H, t}\left(f_{T H}\right)$ still apply at the future date $t+j$. The variables $y_{T H, t+j \mid t}\left(f_{T H}\right)$ and $y_{T H, t+j \mid t}^{*}\left(f_{T H}\right)$ denote the Home and Foreign demands for good $f_{T H}$, and $\widetilde{h}_{T H, t+j \mid t}\left(f_{T H}\right)$ denotes the total labour input used by the firm, if the prices decided at $t$ still apply at date $t+j$.

Output sold at Home and abroad is produced using a common plant or production function:

$$
y_{T H, t}\left(f_{T H}\right)+y_{T H, t}^{*}\left(f_{T H}\right)=z_{T H, t} \cdot \widetilde{h}_{T H, t}\left(f_{T H}\right)^{\alpha},
$$

where the parameter $\alpha$ allows for decreasing returns to labour, and $z_{T H}$ represents technology.

In the Foreign country, the production function and maximization problem of tradeable sector firms $f_{T F}^{*}$ are the same as in the Home country. All parameters are assumed to be the same in both countries and sectors. In particular, I assume that both $\zeta^{*}$ and $\zeta$ (the pass-through elasticity into import prices) are equal to one.

The pricing behaviour and production functions of nontradeable sector firms $f_{N}$ and $f_{N}^{*}$ are as described in this section, except for the fact that nontradeable firms serve only their own domestic market and do not engage in price discrimination. 


\section{Consumption indexes}

Preferences over tradeable and nontradeable goods in the Home country are specified as follows: ${ }^{2}$

$$
C_{t}=\left[(1-\gamma)^{\frac{1}{\phi}}\left(C_{T, t}\right)^{\frac{\phi-1}{\phi}}+\gamma^{\frac{1}{\phi}}\left(C_{N, t}\right)^{\frac{\phi-1}{\phi}}\right]^{\frac{\phi}{\phi-1}}
$$

while preferences over Home and Foreign tradeables are given by:

$$
C_{T, t}=\left[(1-\delta)^{\frac{1}{\theta}}\left(C_{T H, t}\right)^{\frac{\theta-1}{\theta}}+\delta^{\frac{1}{\theta}}\left(C_{T F, t}\right)^{\frac{\theta-1}{\theta}}\right]^{\frac{\theta}{\theta-1}}
$$

The preference weights $\gamma$ and $\delta$ and the substitution elasticities $\phi$ and $\theta$ are the same in both countries.

The consumption sub-indices for the individual varieties are given by CES aggregators, with constant elasticity of substitution $\eta$. Price indexes are defined as the minimal expenditures needed to buy one unit of the corresponding consumption aggregators.

\section{Government budget constraint and money supply}

According to the U.S. Bureau of Economic Analysis (2014), government consumption expenditures consists of services provided to the public without charge. Therefore I assume that the Home and Foreign governments purchase only nontradeable goods produced in their own country. The budget constraint of the Home government at date $t$ is given by: ${ }^{3}$

$$
M_{t}-M_{t-1}=P_{N, t} G_{t}+T R_{t},
$$

where $M$ is money, $P_{N}$ is the aggregate price of nontradeables, $G$ is a CES aggregator of varieties $f_{N}$, with the same elasticity of substitution $\eta$, and $T R$ are government transfers.

\section{Individual preferences and labour supply}

The Home and Foreign countries are populated by a continuum of homogeneous individuals uniformly distributed on $[0,1]$. I discuss only the Home maximisation problem, since it is the same

\footnotetext{
${ }^{2}$ Preferences in the Foreign country are described by the same aggregators.

${ }^{3}$ The Foreign government budget constraint and the public expenditure aggregator are entirely analogous.
} 
in both countries. In each period the individual chooses consumption, real money balances $\frac{M}{P}$ and hours worked in each sector. Real money balances are included in the utility function because of the liquidity services that they provide. Let $\mathbf{h}_{T H}$ and $\mathbf{h}_{N}$ denote total hours supplied to all firms in sectors $T H$ and $N$. Total time available to an employed individual is normalized to one, and total time available to an unemployed individual is denoted with $\tau$. An individual who works incurs a fixed participation or commuting cost $\psi$, measured in units of time. Because of the restriction that labour cannot be supplied to both sectors simultaneously, the individual's consumption possibilities set $\boldsymbol{X}$ in any given period is nonconvex:

$\boldsymbol{X}=\left\{\left(C, \frac{M}{P}, \mathbf{h}_{T H}, \mathbf{h}_{N}\right): C \geq 0, \frac{M}{P} \geq 0,0 \leq \mathbf{h}_{T H} \leq 1-\psi, 0 \leq \mathbf{h}_{N} \leq 1-\psi, \mathbf{h}_{T H} \cdot \mathbf{h}_{N}=0\right\}$

The individual's utility function ${ }^{4}$ is:

$$
U_{0}=E_{0} \sum_{t=0}^{\infty} \beta^{t}\left[\frac{C_{t}^{1-\sigma}-1}{1-\sigma}+\frac{\chi}{1-\varepsilon}\left(\frac{M_{t}}{P_{t}}\right)^{1-\varepsilon}+v\left(\mathbf{h}_{T H, t}, \mathbf{h}_{N, t}\right)\right],
$$

where $\sigma$ and $\varepsilon$ are curvature parameters, and:

$$
v\left(\mathbf{h}_{T H, t}, \mathbf{h}_{N, t}\right)= \begin{cases}\frac{\kappa}{\omega}\left(1-\psi-\mathbf{h}_{T H, t}\right)^{\omega} & \text { if } \mathbf{h}_{T H, t} \neq 0, \\ \frac{\kappa}{\omega}\left(1-\psi-\mathbf{h}_{N, t}\right)^{\omega} & \text { if } \mathbf{h}_{N, t} \neq 0 \\ \frac{\kappa}{\omega}(\tau)^{\omega} & \text { if } \mathbf{h}_{T H, t}=\mathbf{h}_{N, t}=0 .\end{cases}
$$

The parameters $\kappa, \psi$ and $\omega$ can be chosen so as to match the labour supply elasticity and hours worked in the steady state.

The consumption set can be convexified by adding lotteries over the choice of working in the two sectors. In this environment the individual maximises her expected utility, ${ }^{5}$ which is given by:

\footnotetext{
${ }^{4}$ I choose these functional forms because Rogerson's (1988b) aggregation requires separable preferences, and because analogous functional forms (but not the nonconvexity) can be found in the literature; for example, Obstfeld and Rogoff (1995) or Benigno and Thoenissen (2003).

${ }^{5}$ Notice that these preferences are the same as those of a utilitarian household with a unit mass of homogeneous individuals, who assigns a fraction of its members to sector $T H$ and another fraction to sector $N$, pools its members' labour incomes and ensures that each one receives the same level of consumption.
} 


$$
U_{0}=E_{0} \sum_{t=0}^{\infty} \beta^{t}\left[\begin{array}{c}
\frac{C_{t}^{1-\sigma}-1}{1-\sigma}+\frac{\chi}{1-\varepsilon}\left(\frac{M_{t}}{P_{t}}\right)^{1-\varepsilon}+n_{T H, t} \cdot \frac{\kappa}{\omega}\left(1-\psi-\mathbf{h}_{T H, t}\right)^{\omega} \\
+n_{N, t} \cdot \frac{\kappa}{\omega}\left(1-\psi-\mathbf{h}_{N, t}\right)^{\omega} \\
+\left(1-n_{T H, t}-n_{N, t}\right) \cdot \frac{\kappa}{\omega}(\tau)^{\omega}
\end{array}\right]
$$

where $n_{T H}$ and $n_{N}$ are the probabilities of working in the tradeable and nontradeable sectors. Because of the law of large numbers, these are equal to the fractions of individuals at the aggregate level.

The aggregation based on employment lotteries has attracted some objections (Ljungqvist and Sargent 2011), but on the other hand the utility function (9) possesses several advantages. First, it disentangles both margins of labour supply, hours and participation rates. Second, since the probabilities enter linearly, it can be interpreted as average or expected utility. Third, this specification does not impose that sectors pay the same wage. ${ }^{6}$

Individuals can smooth their consumption by trading in a one-period non-contingent real bond, denominated in units of the Home tradeable goods consumption index, sold at the price $P_{T}$. Similarly to Benigno (2001), individuals must pay a small cost in order to undertake a position in the international asset market. ${ }^{7}$ This cost is assumed to be a payment in exchange for intermediation services, offered by financial firms located in both the Home and the Foreign country. Individuals pay this cost only to firms located in their own country.

The period- $t$ budget constraint of the individual in the Home country is as follows:

$$
\begin{gathered}
B_{t} P_{T, t}+\frac{\nu}{C_{0}} B_{t}^{2} P_{T, t}+M_{t} \leq\left(1+r_{t-1}\right) B_{t-1} P_{T, t}+M_{t-1} \\
\quad+T R_{t}-P_{t} C_{t}+n_{T H, t} W_{T H, t} \mathbf{h}_{T H, t}+n_{N, t} W_{N, t} \mathbf{h}_{N, t} \\
\quad+\int_{0}^{1} \Pi_{T H, t}\left(f_{T H}\right) d f_{T H}+\int_{0}^{1} \Pi_{N, t}\left(f_{N}\right) d f_{N}+R_{t},
\end{gathered}
$$

\footnotetext{
${ }^{6}$ In a separate appendix (available on request) I present a two-sector open economy version of Hansen (1985) and Rogerson (1988a), in which individuals can either work a fixed workweek or not at all, and I show that the solution is analogous to the model in which labor cannot be supplied to both sectors simultaneously. Thus, the restriction that individuals can only work in one sector at a time may be seen as an alternative way of generating the same quantitative results as indivisible labor, but without the assumption of a fixed workweek length.

${ }^{7}$ This assumption ensures stationarity of the model and a well-defined steady state, as demonstrated by SchmittGrohe and Uribe (2003).
} 
where $B$ is the internationally traded bond, $\frac{\nu}{C_{0}} B$ is the cost of holding one unit of the bond, ${ }^{8}$ which depends on the positive parameter $\nu, r$ is the real interest rate, $T R$ are government transfers, $W_{T H}$ and $W_{N}$ are the nominal wages paid in the tradeable and nontradeable sector respectively, $\Pi_{T H}\left(f_{T H}\right)$ and $\Pi_{N}\left(f_{N}\right)$ are the profits that the individual receives from firms $f_{T H}$ (tradeable sector) and $f_{N}$ (nontradeable sector), and $R$ represents the rents generated by the financial intermediaries. The internationally traded bond $B$ is in zero net supply worldwide. Nominal wages are flexible.

When both participation rates and hours of work are choice variables the assumption that preferences are separable has important consequences. By combining a few first order conditions of the maximization problem we obtain:

$$
\begin{gathered}
\frac{\kappa}{\omega}\left(1-\psi-\mathbf{h}_{T H, t}\right)^{\omega}+\kappa\left(1-\psi-\mathbf{h}_{T H, t}\right)^{\omega-1} \mathbf{h}_{T H, t}=\frac{\kappa}{\omega}(\tau)^{\omega} \\
\frac{\kappa}{\omega}\left(1-\psi-\mathbf{h}_{N, t}\right)^{\omega}+\kappa\left(1-\psi-\mathbf{h}_{N, t}\right)^{\omega-1} \mathbf{h}_{N, t}=\frac{\kappa}{\omega}(\tau)^{\omega} .
\end{gathered}
$$

Equations (11) and (12) above must have a unique solution, but the solution must be the same in the steady state and in each date $t$. Therefore, in this model hours worked in the two sectors are always constant and equal to each other. ${ }^{9}$ This result in turn implies that the first order conditions with respect to the labour effort reduce to only one equation:

$$
\kappa\left(1-\psi-\mathbf{h}_{0}\right)^{\omega-1} C_{t}^{\sigma}=\frac{W_{T H, t}}{P_{t}}=\frac{W_{N, t}}{P_{t}}
$$

where $\mathbf{h}_{0}$ is endogenously constant. Notice that in Hansen's (1985) model $\mathbf{h}_{0}$ is exogenously given instead. Real wages are equalized between sectors, and in this model output demand determines the amount of the labour input. The aggregate labour supply, ${ }^{10}$ i.e. the supply of

\footnotetext{
${ }^{8}$ If we denote with $\Psi(B) B$ the cost of holding bonds, then the function $\Psi$ must be nonconcave, increasing and continuously differentiable. An additional requirement is that $\Psi(B)=0$ if and only if $B=0$, and $\Psi^{\prime}(B) \neq 0$.

${ }^{9}$ It is possible to ensure that hours worked in the two sectors are different by specifying a different participation cost $\psi$ in the two sectors.

${ }^{10}$ The Frisch elasticity is derived from the first-order conditions for labour effort, holding the marginal utility of wealth constant. From equation (13) we obtain $\frac{\vartheta \frac{W_{t}}{P_{t}}}{\vartheta n_{t}}=0$, therefore the aggregate Frisch elasticity $\frac{\vartheta\left(\mathbf{h}_{0} n_{t}\right)}{\vartheta \frac{W_{t}}{P_{t}}} \cdot \frac{\frac{W_{t}}{P_{t}}}{\left(\mathbf{h}_{0} n_{t}\right)}$ is infinite.
} 
$\mathbf{h}_{0} n_{t} \equiv \mathbf{h}_{0}\left(n_{T H, t}+n_{N, t}\right)$, is infinitely elastic, ${ }^{11}$ as is the supply of $n_{T H, t}$ and $n_{N, t}$.

\section{If labour is supplied to both sectors simultaneously}

The standard assumption in the literature is that individuals can work contemporaneously in both the tradeable and nontradeable sectors. For comparability purposes I keep the same functional forms in both scenarios. The utility function and budget constraint are as follows:

$$
\begin{gathered}
U_{0}=E_{0} \sum_{t=0}^{\infty} \beta^{t}\left[\frac{C_{t}^{1-\sigma}-1}{1-\sigma}+\frac{\chi}{1-\varepsilon}\left(\frac{M_{t}}{P_{t}}\right)^{1-\varepsilon}+\frac{\kappa}{\omega}\left(1-\psi-\mathbf{h}_{T H, t}-\mathbf{h}_{N, t}\right)^{\omega}\right] \\
B_{t} P_{T, t}+\frac{\nu}{C_{0}} B_{t}^{2} P_{T, t}+M_{t} \leq\left(1+r_{t-1}\right) B_{t-1} P_{T, t}+M_{t-1} \\
\quad+T R_{t}-P_{t} C_{t}+W_{t}\left(\mathbf{h}_{T H, t}+\mathbf{h}_{N, t}\right) \\
+\int_{0}^{1} \Pi_{T H, t}\left(f_{T H}\right) d f_{T H}+\int_{0}^{1} \Pi_{N, t}\left(f_{N}\right) d f_{N}+R_{t}
\end{gathered}
$$

Since hours worked enter additively, the individual is indifferent between working in one sector or both, provided the aggregate labour supply $\mathbf{h}_{t} \equiv \mathbf{h}_{T H, t}+\mathbf{h}_{N, t}$ is the same. Notice that in an interior solution sectors must pay the same wage.

It may be possible to interpret (14) as the utility function of a stand-in household, whose hours of work equal aggregate hours in the economy. There are however some unresolved issues with this interpretation. The utility function (14) does not distinguish between the intensive and the extensive margins of labour supply, however, if $\mathbf{h}_{T H, t}$ and $\mathbf{h}_{N, t}$ are to be interpreted as aggregate hours, they must be the outcome of choices made on both margins. If, for example, we regard the hours in (14) as the product of participation rates times hours worked per person, then this specification is neither the average nor the expected utility of the members of the household. More generally, it is not possible to see how the intensive and extensive margins determine the aggregate

\footnotetext{
${ }^{11}$ In a separate appendix I investigate whether the infinite elasticity is due to the employment lottery or the homogeneity of individuals. I show that heterogeneity per se does not guarantee a finite elasticity of labour supply, and what matters in a model with this type of non-convexity is how the aggregate variables are derived from the preferences of heterogeneous individuals. In a utilitarian household solution it is possible to have a finite labour supply elasticity if individuals are heterogeneous. In the equilibrium with employment lotteries the elasticity of labour supply is infinite, even with agent heterogeneity.
} 
hours in (14) without a formal derivation of the utility of the stand-in household from individual preferences.

To examine the implications of (14) for the labour supply elasticity, consider the first order condition with respect to the labour effort:

$$
\kappa\left(1-\psi-\mathbf{h}_{t}\right)^{\omega-1} C_{t}^{\sigma}=\frac{W_{t}}{P_{t}}
$$

from which we obtain the Frisch labor supply elasticity: $\frac{\vartheta \mathbf{h}_{t}}{\vartheta \frac{W_{t}}{P_{t}}} \cdot \frac{\frac{W_{t}}{P_{t}}}{\mathbf{h}_{t}}=\frac{1}{1-\omega} \frac{1-\psi-\mathbf{h}_{t}}{\mathbf{h}_{t}}$. Since $\mathbf{h}_{0}$ is given in the steady state, the Frisch elasticity can be calibrated with the parameter $\omega$. Therefore if $\omega<1$ the labour supply is upward sloping. ${ }^{12}$ Firms decide how aggregate hours worked are allocated between the two sectors.

\section{Calibration}

The calibrated parameter values are shown in Table 1.

\section{TABLE 1 HERE}

The parameter $\sigma$ is the same as in Chari, Kehoe and McGrattan (2002). Given $\sigma$, I choose $\epsilon$ so that the consumption elasticity of money demand is equal to one, and I choose $\kappa$ and $\psi$ so that hours worked in the steady state are equal to $324.8 / 1369$ in both models. ${ }^{13}$

The elasticity of substitution between tradeable and nontradeable goods is as in Obstfeld and Rogoff (2005). I choose a value for the elasticity of substitution between domestic and foreign tradeables that is somehow in the middle of the range of values in the literature. The preference weight for nontradeables $\gamma$ is set between the values suggested by Obstfeld and Rogoff (2007) and Benigno and Thoenissen (2003), and the parametrization of $\delta$, the preference weight for Foreignproduced tradeables, is as in Obstfeld and Rogoff $(2005) .{ }^{14}$ I calibrate the steady state ratios of exogenous technology so that, in both models, the ratio of Home to Foreign tradeable output is

\footnotetext{
${ }^{12}$ Once the Frisch elasticity is chosen, the actual values of $\kappa$ and $\psi$ are irrelevant to the dynamics of the log-linearized model.

${ }^{13}$ These numbers are average hours worked in a year and total hours available, taken from Burnside and Eichenbaum (1996)

${ }^{14}$ The calibrated value for $\delta$ implies that the share of imports over aggregate output is $5 \%$, which is roughly the share of the combined imports from Canada, Japan, Mexico, France, Germany and the UK over U.S. GDP.
} 
equal to one, and the Home and Foreign ratios of tradeable to nontradeable output ${ }^{15}$ are equal to 0.2. Consequently the steady state is the same in both models.

The intermediation cost parameter $\nu$ is chosen so that the spread in the nominal interest rates approximates the value suggested by Benigno (2009). The parameter $\eta$ implies that the steady state markup is about 1.15 , and the probabilities of not changing prices imply an average price duration of about one year. The elasticity of output with respect to hours is calibrated so that, given the mark-up, in the steady state the share of wages in output is equal to 0.7. I assume PCP but I consider alternative pricing assumptions in Section 7.

I compute the time series of technology, money growth and government expenditures for the U.S. and the rest of the world. The rest of the world is an aggregate of Canada, France, Germany, ${ }^{16}$ Japan, Mexico and the UK, which together represented $46 \%$ of the U.S. total trade in goods in 2007. ${ }^{17}$ The combined GDP of these six countries was $104 \%$ of the U.S. GDP in the last quarter of 2007. I compute the tradeable and nontradeable technology series using sectoral data.

Shock properties are estimated by fitting $\mathrm{AR}(1)$ processes to the money growth rates and the logs of technology and government expenditures (all HP-filtered). ${ }^{18}$ Several of the estimated crosscorrelations among the shocks are lower than 0.15 and non-statistically significant, therefore I parameterize them at zero. All the cross-correlations which are instead statistically significant are shown in Table 1, together with all the other estimated shock properties.

I solve the model numerically using Uhlig's "Toolkit" algorithm (1999). The numerical solution is obtained by log-linearising the equations around a deterministic equilibrium or steady state. I assume that in the steady state bond holdings are zero.

\section{Results}

I illustrate the performance of the model of Section 2 against the data and against the standard assumption that individuals supply labour contemporaneously to both sectors, in which case I

\footnotetext{
${ }^{15}$ The ratio of value added in manufacturing over the value added in services is approximately equal to 0.2 in the U.S.. Source: own calculations based on the Groningen 60-Industry Database, http://www.ggdc.net.

${ }^{16}$ East Germany is not included in the time series up until 1990:4.

${ }^{17}$ Author's calculations based on Bureau of Economic Analysis data. China has recently emerged as another top US trading partner, but it was not included in the aggregate of Foreign countries because of the limited availability of data on the Chinese economy.

${ }^{18}$ Details on the construction of the exogenous processes are given in a separate appendix (available on request).
} 
assume that preferences are as in Section 3 and so the labour supply elasticity is finite. I consider two alternative values for the Frisch elasticity ${ }^{19}, 1.5$ and 0.75 , and I report second-order moments ${ }^{20}$ of the finite and the infinite elasticity models in Table 2 .

\section{TABLE 2 HERE}

A critical issue to consider beforehand is the measurement of the aggregate labour input. In the model of Section 2, all variation in the labour input is represented by variation in the extensive margin, or changes in participation rates, so I measure the aggregate labour input with $n_{t}$. On the other hand, if individuals supply labour contemporaneously to both sectors and preferences are as in Section 3, all variation in the labour input is represented by variation in the intensive margin, or changes in hours, so the aggregate labour input is $\mathbf{h}_{t}$. I choose to measure the aggregate labour input in the data with aggregate hours, which are the product of average weekly hours and employment, and therefore reflect changes along both margins. ${ }^{21}$

The other variables of interest are real aggregate output, which is defined as $Y_{t} \equiv P_{T H, 0} Y_{T H, t}+$ $P_{T H, 0}^{*} Y_{T H, t}^{*}+P_{N, 0} Y_{N, t}$, while total tradeable output is $Y_{T H, t}^{T o t} \equiv Y_{T H, t}+Y_{T H, t}^{*}=C_{T H, t}+C_{T H, t}^{*}$. The price index for all Home tradeable goods is defined as the weighted average of the prices paid by domestic and foreign consumers, with weights taken from the steady state:

$$
P_{T H, t}^{T o t} \equiv \frac{P_{T H, t} \cdot Y_{T H 0}+e_{t} P_{T H, t}^{*} \cdot Y_{T H 0}^{*}}{P_{T H 0} \cdot Y_{T H 0}+e_{0} P_{T H 0}^{*} \cdot Y_{T H 0}^{*}} .
$$

The real exchange rate is the ratio of Foreign to Home aggregate price indexes:

$$
R E R_{t} \equiv \frac{e_{t} P_{t}^{*}}{P_{t}}
$$

\footnotetext{
${ }^{19}$ These are steady state values. I choose these two values because most estimates in the macro literature lie in this range. Raffo (2008) reports that the range of estimates for the Frisch elasticity of labour supply is between 1 and 1.5 at the aggregate level. Based on their survey of the literature, Chetty et al. (2011) recommend calibrating macro models to match a Frisch elasticity of aggregate hours of 0.75 . On the other hand, some authors in the literature assume that the disutility from labour is linear, so the Frisch labour supply elasticity is infinite (for example, Cooke 2010).

${ }^{20}$ The statistics of Tables 2-5 were obtained using frequency domain techniques as described in Uhlig (1999). The number of gridpoints used in the computation of the spectral density is 512 . Increasing the number of gridpoints has no significant effect on the model moments up to the second decimal place.

${ }^{21}$ This choice is consistent with many studies, including the indivisible labour literature. For example, Hansen (1985) considers total hours (i.e. aggregate) for persons at work in non-agricultural industries. However, other studies measure $\mathbf{h}_{t}$ with employment data (for example, Chari, Kehoe and McGrattan 2002).
} 
An increase (fall) in this quantity is a "depreciation" ("appreciation"). The (Home) terms of trade is the relative price of imports over exports:

$$
T_{t} \equiv \frac{P_{T F, t}}{e_{t} P_{T H, t}^{*}}
$$

I consider two measures of net exports: the ratio of nominal net exports to nominal GDP:

$$
N X_{t} \equiv \frac{e_{t} P_{T H, t}^{*} Y_{T H, t}^{*}-P_{T F, t} Y_{T F, t}}{P_{T H, t} Y_{T H, t}+e_{t} P_{T H, t}^{*} Y_{T H, t}^{*}+P_{N, t} Y_{N, t}},
$$

and the ratio of real net exports to real GDP:

$$
N X Q T Y_{t} \equiv \frac{P_{T H, 0}^{*} Y_{T H, t}^{*}-P_{T F, 0} Y_{T F, t}}{P_{T H, 0} Y_{T H, t}+P_{T H, 0}^{*} Y_{T H, t}^{*}+P_{N, 0} Y_{N, t}} .
$$

Changes in $N X_{t}$ are determined by changes in quantities (exports and imports of goods), and changes in relative prices (the terms of trade and the relative price of nontradeables), while $N X Q T Y_{t}$ is unaffected by the changes in relative prices.

Given the focus of this paper on the tradeable and nontradeable sectors, I also report sectoral statistics $^{22}$ in Table 2 . In the data, the tradeable sector is represented by manufacturing, and the nontradeable sector by services. ${ }^{23}$ The Frisch elasticity does not affect the sectoral statistics: the second-order moments generated by the infinite elasticity model are very close to the ones obtained with a finite Frisch elasticity. ${ }^{24}$ Moreover, both the infinite and the finite elasticity models are able to generate more volatile employment and output in the tradeable sector than in the nontradeable sector. ${ }^{25}$

Table 2 shows that the Frisch elasticity has a significant impact on the volatility of wages and inflation rates (or prices). To understand why, it may be useful to examine, by means of a variance decomposition exercise, which shocks are the main sources of business cycle fluctuations.

\footnotetext{
${ }^{22}$ The sectoral statistics presented in Table 2 differ from the ones in Devereux and Hnatkovska (2012). This is because they report the properties of sectoral shares, while I compute the statistics using sectoral output levels.

${ }^{23}$ Notice that, since some manufacturing output is nontradeable, and some services are actually traded internationally, the data is an imprecise measure of tradeable and nontradeable output.

${ }^{24}$ The standard deviation of average weekly hours of production workers relative to output in the US is 0.29 (source: own calculations based upon BLS data).

${ }^{25}$ In Povoledo (2013) I compare the data at different frequencies and sectoral classifications, and I show that tradeable sector variables are always more volatile than nontradeable sector variables.
} 


\section{TABLE 3 HERE}

As shown in Table 3, the sum of Home and Foreign money shocks explains the largest proportion of the variance of all variables. The impact of technology shocks on sectoral employment is significant, and yet lower than the combined impact of Home and Foreign money shocks. Therefore monetary shocks are the main cause of business cycle fluctuations.

To understand why the Frisch elasticity affects the volatility of wages (Table 2), we can focus only on monetary shocks, as these explain more than $80 \%$ of their variance. The larger is the labour supply elasticity and the flatter is the labour supply curve, so real wages respond less after a shock affecting the labour demand. This fact is confirmed by Table 2: the standard deviation of wages relative to output falls when the Frisch elasticity is higher. ${ }^{26}$ However, since wages affect marginal costs, the lower is the response of wages, and the lower is the response of prices after a shock, because firms optimally choose not to raise their prices much if wages do not rise much. Therefore, the higher is the Frisch elasticity, the less responsive are prices.

On the other hand, the labour supply elasticity has almost no effect on the volatility of the open economy variables. For example, if the Frisch elasticity increases from 0.75 to infinity, the volatility of real wages decreases by $32 \%$ (from 4.13 to 2.79 ), and the volatility of inflation decreases by $16 \%$ (from 0.76 to 0.64 ), ${ }^{27}$ but the decreased volatility of wages and prices has almost no effect on the volatility of the terms of trade, and no effect at all on the volatility of real (NXQTY) and nominal net exports $(N X)$. The nominal exchange rate is affected, but its volatility decreases only by $6 \%$ (from 4.30 to 4.06 ). Therefore, there is a disconnect between the open economy variables and the response of wages. Moreover, the relationship between the speed of price adjustment (or the volatility of inflation) and the volatility of the nominal exchange rate is weak.

We can further understand the results of Table 2 by inspecting the impulse responses of the open economy variables to Home monetary shocks (Figure 1). I do not present the responses to Foreign shocks since they are qualitatively symmetrical to the responses to Home shocks. ${ }^{28}$

\footnotetext{
${ }^{26}$ On the other hand, when the Frisch elasticity increases, the increased volatility of employment is matched by an increase in the volatility of output, thus the standard deviation of employment relative to output is almost unaffected.

${ }^{27}$ The decrease in the volatility of tradeable goods inflation $\pi_{T H}^{T o t}$ and aggregate inflation $\pi$ may partially be due to the change in the volatility of the nominal exchange rate. However, nontradeable goods inflation $\pi_{N}$ is not directly affected by changes in the exchange rate, and its volatility decreases by $19 \%$ (from 0.62 to 0.51 ).

${ }^{28}$ They are not perfectly symmetrical because the estimated AR parameters of the shocks are not identical. However, since the Home and Foreign countries share the same structural parameters, such departures from perfect symmetry are not significant. The responses of all the other variables to the shocks are available on request.
} 


\section{FIGURE 1 HERE}

A positive shock to the Home money growth rate causes a nominal depreciation of the Home currency and an increase in Home prices. Because of price rigidity, the response of the nominal exchange rate is stronger than the increase of Home prices, therefore a positive Home money shocks brings about a depreciation (increase) of both the real exchange rate and the terms of trade (Figure 1). Moreover, because of the expenditure-switching effect which characterizes PCP models (the terms of trade depreciation causes the foreign and domestic demand to shift towards Home tradeable goods), a positive Home monetary shock causes an increase in real net exports.

However, the increase of Home prices dampens the effect of the nominal depreciation on the real exchange rate and on the terms of trade. Therefore, after an increase in the speed of price adjustment, we would expect the response of the real exchange rate and the terms of trade to the monetary shocks to be comparatively smaller and less persistent. One strategy for controlling the speed of price adjustment is to vary the Frisch elasticity of labour supply, which becomes infinite when there are nonconvexities affecting the labour supply. Figure 1 shows that this strategy is ineffective: the Frisch elasticity of labour supply almost has no effect on the impulse responses of the open economy variables to monetary shocks, which are the main source of business cycle fluctuations.

I also plot the autocorrelation functions of the open economy variables in Figure 2. The autocorrelation functions of the real and nominal exchange rates generated by the final and the infinite elasticity models match reasonably well their empirical counterparts, while the empirical autocorrelations of real net exports and the terms of trade do not die out as fast as the model-generated autocorrelations. But the persistence of the open economy variables cannot be increased by the infinite labour supply elasticity, since it has almost no effect on the autocorrelation at all lags.

\section{FIGURE 2 HERE}

To understand why there is a disconnect between the open economy variables and the response of wages (or, between the open economy variables and the elasticity of labour supply), it is useful to derive an expression for the nominal exchange rate under a few simplifying assumptions. From the log-linearized first-order conditions for bond and money holdings in the Home and Foreign countries we can derive the following expressions: 


$$
\begin{gathered}
\sigma\left(E_{t} \widehat{C}_{t+1}-E_{t} \widehat{C}_{t+1}^{*}\right)=\sigma\left(\widehat{C}_{t}-\widehat{C}_{t}^{*}\right)+E_{t} \widehat{e}_{t+1}-\widehat{e}_{t}+\left(\widehat{P}_{t}-\widehat{P}_{t}^{*}\right)-\left(E_{t} \widehat{P}_{t+1}-E_{t} \widehat{P}_{t+1}^{*}\right), \\
\varepsilon\left(\widehat{M}_{t}-\widehat{M}_{t}^{*}\right)-\varepsilon\left(\widehat{P}_{t}-\widehat{P}_{t}^{*}\right)=\frac{1}{1-\beta}\left[\begin{array}{c}
\sigma\left(\widehat{C}_{t}-\widehat{C}_{t}^{*}\right)-\sigma \beta\left(E_{t} \widehat{C}_{t+1}-E_{t} \widehat{C}_{t+1}^{*}\right) \\
+\beta\left(\widehat{P}_{t}-\widehat{P}_{t}^{*}\right)-\beta\left(E_{t} \widehat{P}_{t+1}-E_{t} \widehat{P}_{t+1}^{*}\right)
\end{array}\right] .
\end{gathered}
$$

By substituting (22) into (23) and assuming for simplicity $\sigma=\varepsilon=1$ we obtain:

$$
\left(\widehat{M}_{t}-\widehat{M}_{t}^{*}\right)-\left(\widehat{P}_{t}-\widehat{P}_{t}^{*}\right)=\left(\widehat{C}_{t}-\widehat{C}_{t}^{*}\right)+\frac{\beta}{1-\beta}\left(\widehat{e}_{t}-E_{t} \widehat{e}_{t+1}\right)
$$

If $\zeta=\zeta^{*}=1$ and countries are symmetric, then:

$$
\widehat{P}_{t}-\widehat{P}_{t}^{*}=k_{2} \widehat{e}_{t}-k_{2}(1-2 \delta)\left(\widehat{P}_{T F, t}-\widehat{P}_{T H, t}\right)+\left(1-k_{2}\right)\left(\widehat{P}_{N, t}-\widehat{P}_{N, t}^{*}\right)
$$

where $k_{2} \equiv\left(P_{T 0} C_{T 0}\right) /\left(P_{0} C_{0}\right)$ is the steady state ratio of tradeable consumption over total consumption. By substituting (25) into equation (24) and solving forward we obtain:

$$
\widehat{e}_{t}=\frac{1}{k_{2}}\left[\begin{array}{c}
k_{2}(1-2 \delta)\left(\widehat{P}_{T F, t}-\widehat{P}_{T H, t}\right)-\left(1-k_{2}\right)\left(\widehat{P}_{N, t}-\widehat{P}_{N, t}^{*}\right) \\
-\left(\widehat{C}_{t}-\widehat{C}_{t}^{*}\right)+(1-\beta) E_{t} \sum_{j=0}^{\infty} \beta^{j}\left(\widehat{M}_{t+j}-\widehat{M}_{t+j}^{*}\right)
\end{array}\right]
$$

Equation (26) above illustrates why the labour supply elasticity does not significantly affect the nominal exchange rate. It shows that the response of the nominal exchange rate depends on the current and expected future nominal money supply in the two countries, and on the current consumption and nontradeable goods price differentials. Since the labour supply elasticity has a modest impact on the response of current period consumption, it can affect only Equation (26) through the response of nontradeable good prices. However, only the contemporaneous response of nontradeable good prices affects Equation (26), therefore, increasing the amount of price adjustment by means of the Frisch elasticity has a limited impact on Equation (26). This is because the future path of prices, which depends on the labour supply elasticity, does not enter Equation (26). 
Equations (18) and (19) show why the labour supply elasticity does not significantly affect the real exchange rate and the terms of trade. Given that the response of the nominal exchange rate to monetary shocks is not affected by the Frisch elasticity, the labour supply elasticity can affect only equations (18) and (19) through the response of relative prices. However, an increase or decrease in the amount of price adjustment not only affects the response of Home prices to monetary shocks, but also the response of Foreign prices, therefore an increase in the response of the denominator is offset by a similar increase in the response of the numerator (and vice versa). As a result, the Frisch elasticity has a modest impact on the response of international relative prices. Finally, since the Frisch elasticity does not significantly affect the nominal exchange rate and the terms of trade, it does not affect significantly real and nominal net exports.

\section{The responses to technology and government expenditure shocks}

The responses of the open economy variables to technology and government expenditure shocks are far smaller in magnitude than the responses to monetary shocks (Figures 3 to 5 ). Moreover, the estimated volatility of technology and government shocks is lower than the volatility of monetary shocks (Table 1). Therefore, the contribution of technology and government shocks to the variance of the open economy variables is far smaller than the contribution of monetary shocks (Table 3). On the other hand, the Frisch elasticity of labour supply affects the responses to technology and government shocks more than it affects the responses to monetary shocks.

\section{FIGURES 3-5 HERE}

Looking at Figures 3 to 5 , we can notice that the response of the nominal exchange rate to technology and government expenditure shocks is generally more muted than the responses of the real exchange rate and the terms of trade. This implies that technology and government expenditure shocks affect the real exchange rate and the terms of trade primarily through their impact on relative prices, not much through the nominal exchange rate. Therefore, since the Frisch elasticity affects the speed of price adjustment, it plays an important role in the transmission of technology and government expenditure shocks to the real exchange rate and the terms of trade. 
Consider first a positive Home tradeable technology shock, which causes a decrease in the demand for labour, and consequently a fall in the Home wage rate and a decrease in the price of Home tradeable goods. Since the price of Home exports falls, the terms of trade increases in both the finite and the infinite elasticity models (Figure 3). However, if the labour supply is very elastic, the fall in wages is relatively modest. Therefore, the more elastic is the labour supply, and the smaller is the fall in Home marginal cost and tradeable goods prices. As a result, the terms of trade increases less in the infinite elasticity model because the price of Home exports (the denominator of Equation 19) falls less. Moreover, as demand switches towards the cheaper Home tradeables, the prices of the other Home goods fall as well. The indirect effect of technology shocks on the other goods' prices is controlled by the Frisch elasticity. In the infinite elasticity model the prices of the other Home goods decrease less, thus the real exchange rate increases less (Figure 3).

Consider now a positive Home nontradeable technology shock, which causes a decrease of the price of Home nontradeable goods. Since nontradeables constitute the largest share of Home consumption, the Home aggregate price index decreases, consequently the real exchange rate increases, but more so in the finite elasticity model (Figure 4), because of the faster speed of price adjustment. Moreover, as demand shifts towards the cheaper nontradeables, Home tradeable output falls, consequently the marginal cost of producing tradeables falls. Home tradeable goods producers lower their prices, including the price of Home exports, therefore the terms of trade is also affected by the nontradeable technology shock (Figure 4). The terms of trade increase is strong in the finite elasticity model because the speed of adjustment of tradeable goods prices is faster. On the other hand, price effects are more muted in the infinite elasticity model, so the response of the terms of trade is closer to the response of the nominal exchange rate.

Finally, after a positive government expenditure shock the price of Home nontradeables increases (because the government buys more of them), and the prices of all the other Home goods increase (because Home consumers substitute away from nontradeables). As a result, both the real exchange rate and the terms of trade decrease, more so in the finite elasticity model (Figure 5). 


\section{Robustness}

In this Section I consider how the pricing assumption affects the second-order moments of the model. I consider two alternative pricing assumptions: (1) LCP in both countries; and (2) an asymmetric scenario in which Home producers use PCP and Foreign producers use LCP when selling their goods to the other country. I focus only on the major changes in the second-order moments.

\section{TABLES 4 and 5 HERE}

Under LCP the Frisch elasticity significantly affects the volatility of wages and inflation rates, but it has a modest impact on the open economy variables (Table 4). Therefore, there is a disconnect between the response of wages and the volatility of the open economy variables in both the LCP and the PCP scenarios.

It is possible to understand the link between price adjustment and the nominal exchange rate by examining the model equations under LCP. If $\zeta=\zeta^{*}=0$, the log-linearised optimality conditions of tradeable sector firms imply:

$$
\widehat{e}_{t}=\widehat{P}_{T H, t}-\widehat{P}_{T H, t}^{*}+\frac{1}{1-\varphi \beta} \frac{\varphi}{1-\varphi}\left[\pi_{T H, t}-\pi_{T H, t}^{*}-\beta E_{t} \pi_{T H, t+1}+\beta E_{t} \pi_{T H, t+1}^{*}\right],
$$

where $\pi_{T H}$ and $\pi_{T H}^{*}$ denote respectively the growth rates of $P_{T H}$ (the price paid by Home consumers) and $P_{T H}^{*}$ (the price paid by Foreign consumers). ${ }^{29}$ Equation (27) shows that there is a causal relationship between price adjustment at date $t$ and the nominal exchange rate. However, the future path of prices has a limited impact on today's exchange rate, because current and future inflation rates enter Equation (27) with opposite sign.

Neither PCP nor LCP explain the evidence on exchange rate pass-through, but there is no consensus yet on the correct pricing assumption. Using micro data on import and export prices, recently Gopinath and Rigobon (2008), and Gopinath, Itskhoki and Rigobon (2010) have shown that for the United States there is PCP in exports and LCP in imports. Therefore, I also consider an asymmetric scenario with $\zeta^{*}=1$ and $\zeta=0$ and present the results in Table 5 .

\footnotetext{
${ }^{29}$ Under LCP, the price paid by Foreign consumers is not directly affected by the nominal exchange rate.
} 
Under the asymmetric scenario, the standard deviations of wages, consumption, real net exports and the nominal exchange rate are closer to the data than under the PCP or LCP scenarios. On the other hand, the standard deviation of the terms of trade is too low, and net exports are procyclical (instead of countercyclical, as in the data). The asymmetric scenario combines both PCP and LCP so it shares some of the features of both, in particular, we can notice that the Frisch elasticity again has a modest impact on the volatility and correlations of the open economy variables.

Taken together, the results of Tables 2, 4 and 5 show that the Frisch elasticity affects the standard deviation of wages and inflation, but it does not have a significant effect on the moments of the open economy variables. ${ }^{30}$ This finding is robust to the pricing assumption, and it implies the existence of a disconnect between the response of wages and the open economy variables. The relationship between the volatility of price changes (or the volatility of inflation) and the volatility of the nominal exchange rate is weak under all three scenarios.

\section{Conclusion}

The challenge of building macroeconomic models that are consistent with the microeconometric evidence has generated renewed interest on indivisible labour. However, indivisible labour is only one type of nonconvexity affecting the labour supply. In models with sectors, such as many international macro models, a nonconvexity arises whenever individuals cannot work in two or more sectors at the same time.

It is fair to say that open economy macroeconomics has not been affected yet by the debate on the microfoundations of aggregate labour supply. Perhaps the explanation is that a model with two countries and two sectors is inherently larger than the closed economy, one sector models typically analysed in the existing literature on nonconvexities in labour supply. Analytical tractability is understandably a deciding factor.

This paper shows that it is possible to deal with the restriction that individuals cannot contemporaneously work in two sectors at the same time without sacrificing analytical tractability. To simplify aggregation I use lotteries with complete markets. One drawback of this approach is that

\footnotetext{
${ }^{30}$ The exceptions are the correlation between real net exports and output under LCP, and the correlation between the terms of trade and output under LCP under the asymmetric scenario (Tables 4 and 5). However, most moments of the open economy variables are unaffected or only mildly affected by the Frisch elasticity.
} 
the elasticity of labour supply becomes infinite. This paper presents an analysis of the consequences of varying the labour supply elasticity in open economy models.

One advantage of this approach is that the utility function features both the intensive (hours) and the extensive (participation rates) margins of labour supply. Since individuals cannot work in two sectors at the same time, exogenous shocks trigger a reallocation of workers between sectors, which may be a costly or lengthy process. Therefore, it may be interesting to extend the model by considering such costs or delays, and to analyse how the transmission of shocks or the BalassaSamuelson effect are affected by them. I leave these issues for future research. 


\section{References}

Basu, Parantap, and Robert Kollmann (2013). "Productive Government Purchases and The Real Exchange Rate.” The Manchester School, vol. 81, pages 461-469.

Benigno, Gianluca, and Christoph Thoenissen (2003). "Equilibrium Exchange Rates and Supply-Side Performance." Economic Journal, vol. 113(486), pages C103-C124.

Benigno, Pierpaolo (2009). "Price Stability with Imperfect Financial Integration." Journal of Money, Credit and Banking, vol. 41(s1), pages 121-149.

Betts, Caroline, and Michael B. Devereux (2000). "Exchange Rate Dynamics in a Model of Pricing-to-Market.” Journal of International Economics, vol. 50(1), pages 215-244.

Betts, Caroline, and Michael B. Devereux (1996). "The Exchange Rate in a Model of Pricingto-Market." European Economic Review, vol. 40(3-5), pages 1007-1021.

Burnside, Craig, and Martin Eichenbaum (1996). "Factor-Hoarding and the Propagation of Business-Cycle Shocks.” American Economic Review, vol. 86(5), pages 1154-74.

Chari, V. V., Patrick J. Kehoe and Ellen R. McGrattan (2002). "Can Sticky Price Models Generate Volatile and Persistent Real Exchange Rates?" Review of Economic Studies, vol. 69(3), pages 533-63.

Chari, V. V., Patrick J. Kehoe and Ellen R. McGrattan (2000). "Sticky Price Models of the Business Cycle: Can the Contract Multiplier Solve the Persistence Problem?" Econometrica, vol. 68(5), pages 1151-1180.

Chetty, Raj, Adam Guren, Day Manoli and Andrea Weber (2011). "Are Micro and Macro Labor Supply Elasticities Consistent? A Review of Evidence on the Intensive and Extensive Margins." American Economic Review, vol. 101(3), pages 471-75.

Christiano, Lawrence J., Mathias Trabandt and Karl Walentin (2010). "DSGE Models for Monetary Policy Analysis." In Benjamin M. Friedman and Michael Woodford. Handbook of Monetary Economics, edition 1, vol. 3, ch. 7. Elsevier, pages 285-367.

Cooke, Dudley (2010). "Opennes and Inflation." Journal of Money, Credit, and Banking, vol. $42(2-3)$, pages $267-287$.

Corsetti, Giancarlo, Luca Dedola and Sylvain Leduc (2008). "High Exchange-Rate Volatility and Low Pass-Through." Journal of Monetary Economics, vol. 55(6), pages 1113-1128. 
Corsetti, Giancarlo, Philippe Martin, and Paolo Pesenti (2007). "Productivity, Terms of Trade and the 'Home Market Effect'." Journal of International Economics, vol. 73(1), pages 99-127.

Corsetti, Giancarlo, and Paolo Pesenti (2005). "International Dimensions of Optimal Monetary Policy." Journal of Monetary Economics, vol. 52(2), pages 281-305.

Corsetti, Giancarlo, and Paolo Pesenti (2001). "Welfare and Macroeconomic Interdependence." The Quarterly Journal of Economics, vol. 116(2), pages 421-445.

Devereux, Michael B., and Viktoria Hnatkovska (2012). "The Extensive Margin, Sectoral Shares, and International Business Cycles." Canadian Journal of Economics, vol. 45(2), pages 509-534.

Galí, Jordi, and Tommaso Monacelli (2005). "Monetary Policy and Exchange Rate Volatility in a Small Open Economy." Review of Economic Studies, vol. 72(3), pages 707-734.

Gopinath, Gita, Oleg Itskhoki, and Roberto Rigobon (2010). "Currency Choice and Exchange Rate Pass-Through.” American Economic Review, vol. 100(1), pages 304-36.

Gopinath, Gita, and Roberto Rigobon (2008). "Sticky Borders." The Quarterly Journal of Economics, vol. 123(2), pages 531-575.

Greenwood, Jeremy, Zvi Hercowitz and Gregory W. Huffman (1988). "Investment, Capacity Utilization, and the Real Business Cycle." American Economic Review, vol. 78(3), pages 402-17.

Hansen, Gary D. (1985). "Indivisible Labor and the Business Cycle." Journal of Monetary Economics, vol. 16(3), pages 309-327.

Hodrick, Robert J., and Edward C Prescott (1997). "Postwar U.S. Business Cycles: An Empirical Investigation.” Journal of Money, Credit and Banking, vol. 29(1), pages 1-16.

Janko, Zuzana (2011). "A dynamic small open economy model with involuntary unemployment." Canadian Journal of Economics, vol. 44, pages 1350-1368.

Kollmann, Robert (2010). "Government Purchases and the Real Exchange Rate." Open Economies Review, vol. 21(1), pages 49-64.

Kollmann, Robert (2001). "The Exchange Rate in a Dynamic-Optimizing Business Cycle Model with Nominal Rigidities: A Quantitative Investigation." Journal of International Economics, vol. 55(2), pages 243-262.

Ljungqvist, Lars, and Thomas J. Sargent (2011). "A Labor Supply Elasticity Accord?" American Economic Review, 101(3), pages 487-91. 
Ljungqvist, Lars, and Thomas J. Sargent (2005). "Lotteries for Consumers versus Lotteries for Firms." In Kehoe, Timothy J.; Srinivasan, T. N.; and Whalley, John. Frontiers in Applied General Equilibrium Modeling. Cambridge University Press, pages 119-126.

Morshed, A. K. Mahbub, and Stephen J. Turnovsky (2011). "Real Exchange Rate Dynamics: The Role of Elastic Labor Supply." Journal of International Money and Finance, vol. 30(7), pages $1303-1322$.

Mulligan, Casey B. (2001). "Aggregate Implications of Indivisible Labor." The B.E. Journal of Macroeconomics, Advances in Macroeconomics, vol. 1(1), pages 1-35.

Obstfeld, Maurice, and Kenneth Rogoff (2007). "The Unsustainable U.S. Current Account Position Revisited." NBER Chapters, in: G7 Current Account Imbalances: Sustainability and Adjustment, pages 339-376, National Bureau of Economic Research.

Obstfeld, Maurice, and Kenneth Rogoff (2005). "Global Current Account Imbalances and Exchange Rate Adjustments." Brookings Papers on Economic Activity, vol. 36(1), pages 67-146.

Obstfeld, Maurice, and Kenneth Rogoff (2001). "The Six Major Puzzles in International Macroeconomics: Is There a Common Cause?" NBER Chapters, in: NBER Macroeconomics Annual 2000, vol. 15, pages 339-412, National Bureau of Economic Research.

Obstfeld, Maurice, and Kenneth Rogoff (2000). "New Directions for Stochastic Open Economy Models." Journal of International Economics, vol. 50(1), pages 117-153.

Obstfeld, Maurice, and Kenneth Rogoff (1995). "Exchange Rate Dynamics Redux." Journal of Political Economy, vol. 103(3), pages 624-60.

Povoledo, Laura (2013). "A Note on The Volatility Of The Tradeable And Nontradeable Sectors." Macroeconomic Dynamics, vol. 17(5), pages 1158 - 1168.

Prescott, Edward C. (2004). "The Transformation of Macroeconomic Policy and Research." Nobel Prize in Economics documents 2004-7, Nobel Prize Committee. [http://www.nobelprize.org/nobel_prizes/e lecture.pdf]

Raffo, Andrea (2008). "Net exports, consumption volatility and international business cycle models." Journal of International Economics, vol. 75(1), pages 14-29.

Rogerson, Richard (1988a). "Indivisible Labor, Lotteries and Equilibrium." Journal of Monetary Economics, vol. 21(1), pages 3-16.

Rogerson, Richard (1988b). "Recursive Competitive Equilibrium in Multi-sector Economies." 
International Economic Review, vol. 29(3), pages 419-30.

Rogerson, Richard, and Johanna Wallenius (2009). "Micro and Macro Elasticities in a Life Cycle Model with Taxes." Journal of Economic Theory, vol. 144(6), pages 2277-2292.

Sutherland, Alan (2005). "Incomplete Pass-Through and the Welfare Effects of Exchange Rate Variability." Journal of International Economics, vol. 65(2), pages 375-399.

Uhlig, Harald. (1999). "A Toolkit for Analizing Nonlinear Dynamic Stochastic Models Easily." In Computational Methods for the Study of Dynamic Economies, edited by Ramon Marimon and Andrew Scott, pp. 30-61. Oxford: Oxford University Press.

U.S. Bureau of Economic Analysis (BEA). (2014). "Government Consumption Expenditures and Gross Investment." In "Concepts and Methods of the U.S. National Income and Product Accounts," Washington, DC: BEA. 
Table 1: Parameter values

\begin{tabular}{|c|c|}
\hline Utility & $\beta=0.99, \sigma=\varepsilon=5, \mathbf{h}_{0}=0.24$ \\
\hline Consumption indexes & $\phi=1, \theta=1, \gamma=0.70, \delta=0.30$ \\
\hline Asset market & $\nu=0.005$ \\
\hline Firms & $\begin{array}{l}\varphi=0.75, \eta=7.88, \alpha=0.8 \\
\zeta=\zeta^{*}=1(\mathrm{PCP})\end{array}$ \\
\hline \multicolumn{2}{|c|}{ Exogenous processes: $\widehat{x}_{t}=\bar{x}+\rho \cdot \widehat{x}_{t-1}+\epsilon_{t}$} \\
\hline Home money growth & $\rho=0.4355, \operatorname{var}(\epsilon)=(0.0093)^{2}$ \\
\hline Foreign money growth & $\rho=0.3473, \operatorname{var}(\epsilon)=(0.0081)^{2}$ \\
\hline Home tradeable technology & $\rho=0.8263, \operatorname{var}(\epsilon)=(0.0080)^{2}$ \\
\hline Foreign tradeable technology & $\rho=0.8312, \operatorname{var}(\epsilon)=(0.0098)^{2}$ \\
\hline Home nontradeable technology & $\rho=0.8264, \operatorname{var}(\epsilon)=(0.0035)^{2}$ \\
\hline Foreign nontradeable technology & $\rho=0.5799, \operatorname{var}(\epsilon)=(0.0047)^{2}$ \\
\hline Home government expenditure & $\rho=0.6746, \operatorname{var}(\epsilon)=(0.0012)^{2}$ \\
\hline Foreign government expenditure: & $\rho=0.6449, \operatorname{var}(\epsilon)=(0.0015)^{2}$ \\
\hline \multicolumn{2}{|l|}{ Cross-correlations $\operatorname{corr}\left(\epsilon, \epsilon^{\prime}\right)$ : } \\
\hline \multicolumn{2}{|c|}{$\operatorname{corr}($ Home money growth, Home nontrad. tech. $)=0.3766$} \\
\hline \multicolumn{2}{|c|}{$\operatorname{corr}($ Home money growth, Home gov. exp.) $=0.1853$} \\
\hline \multicolumn{2}{|c|}{$\operatorname{corr}($ Home money growth, Foreign trad. tech.) $=-0.3589$} \\
\hline \multicolumn{2}{|c|}{$\operatorname{corr}($ Home money growth, Foreign gov. exp.) $=-0.1608$} \\
\hline \multicolumn{2}{|c|}{$\operatorname{corr}($ Home trad. tech., Foreign trad. tech. $)=0.3916$} \\
\hline \multicolumn{2}{|c|}{$\operatorname{corr}($ Home nontrad. tech., Home gov. exp.) $=0.5746$} \\
\hline \multicolumn{2}{|c|}{$\operatorname{corr}($ Home nontrad. tech., Foreign trad. tech.) $=-0.2626$} \\
\hline \multicolumn{2}{|c|}{ corr(Home gov. exp., Foreign trad. tech.) $=-0.1945$} \\
\hline \multicolumn{2}{|c|}{$\operatorname{corr}($ Foreign trad. tech., Foreign nontrad. tech.) $=0.4128$} \\
\hline \multicolumn{2}{|c|}{$\operatorname{corr}$ (Foreign nontrad. tech., Foreign gov. exp.) $=-0.1817$} \\
\hline
\end{tabular}


Table 2: Business cycle statistics

\begin{tabular}{|c|c|c|c|c|c|c|c|c|c|c|}
\hline Standard deviations ${ }^{a}$ & $n$ & $\frac{W}{P}$ & $C$ & $\pi$ & $N X$ & $R N X$ & $T$ & $R E R$ & $e$ & \\
\hline U.S. data & 1.41 & 4.08 & 0.77 & 0.33 & 0.33 & 0.28 & 1.77 & 4.86 & 4.78 & \\
\hline Infinite elasticity & 1.24 & 2.79 & 0.56 & 0.64 & 0.19 & 0.49 & 3.37 & 2.74 & 4.06 & \\
\hline Frisch $=1.5$ & 1.24 & 3.44 & 0.56 & 0.70 & 0.19 & 0.49 & 3.37 & 2.73 & 4.19 & \\
\hline Frisch $=0.75$ & 1.23 & 4.13 & 0.56 & 0.76 & 0.19 & 0.49 & 3.36 & 2.72 & 4.30 & \\
\hline Autocorrelations & $n$ & $\frac{W}{P}$ & $C$ & $\pi$ & $N X$ & $R N X$ & $T$ & $R E R$ & $e$ & \\
\hline U.S. data & 0.91 & 0.96 & 0.84 & 0.22 & 0.79 & 0.86 & 0.83 & 0.82 & 0.82 & \\
\hline Infinite elasticity & 0.65 & 0.66 & 0.66 & 0.38 & 0.66 & 0.66 & 0.67 & 0.66 & 0.72 & \\
\hline Frisch $=1.5$ & 0.64 & 0.65 & 0.65 & 0.40 & 0.65 & 0.65 & 0.65 & 0.65 & 0.71 & \\
\hline Frisch $=0.75$ & 0.63 & 0.64 & 0.65 & 0.40 & 0.64 & 0.64 & 0.64 & 0.64 & 0.72 & \\
\hline Cross-correlations & $n, Y$ & $\frac{W}{P}, Y$ & $C, Y$ & $\pi, Y$ & $N X, Y$ & $R N X, Y$ & $T, Y$ & $R E R, Y$ & $e, Y$ & \\
\hline U.S. data & 0.80 & 0.20 & 0.81 & 0.45 & -0.50 & -0.39 & 0.09 & 0.11 & 0.09 & \\
\hline Infinite elasticity & 0.80 & 0.94 & 0.94 & 0.91 & 0.92 & 0.92 & 0.92 & 0.92 & 0.82 & \\
\hline Frisch $=1.5$ & 0.79 & 0.95 & 0.94 & 0.92 & 0.92 & 0.92 & 0.92 & 0.92 & 0.80 & \\
\hline Frisch $=0.75$ & 0.77 & 0.94 & 0.94 & 0.92 & 0.92 & 0.92 & 0.92 & 0.92 & 0.78 & \\
\hline \multicolumn{11}{|c|}{ Sectoral standard deviations $^{a}$} \\
\hline \& cross-correlations & $Y_{T H}^{T o t}$ & $Y_{N}$ & $\pi_{T H}^{T o t}$ & $\pi_{N}$ & $n_{T H}$ & $n_{N}$ & $Y_{T H}^{T o t}, Y$ & $Y_{N}, Y$ & $n_{T H}, Y$ & $n_{N}, Y$ \\
\hline U.S. data & 1.99 & 0.40 & 0.66 & 0.35 & 1.57 & 0.71 & 0.90 & 0.49 & 0.82 & 0.74 \\
\hline Infinite elasticity $^{b}$ & 1.40 & 0.86 & 0.55 & 0.51 & 2.37 & 0.99 & 0.97 & 0.99 & 0.69 & 0.73 \\
\hline Frisch $=1.5^{b}$ & 1.40 & 0.86 & 0.61 & 0.57 & 2.39 & 0.98 & 0.97 & 0.99 & 0.67 & 0.71 \\
\hline Frisch $=0.75^{b}$ & 1.40 & 0.86 & 0.67 & 0.62 & 2.42 & 0.97 & 0.97 & 0.98 & 0.66 & 0.69 \\
\hline
\end{tabular}

NOTE: Data moments have been computed using quarterly series for the period 1980:1 to 2007:4 (but for wages the period is 1981:2 to 2005:4). Data sources and calculations are explained in the Appendix. All moments have been computed from logged and H-P-filtered series, except $N X$ and $R N X$, which are HP-filtered but not logged. The variables $\pi, \pi_{T H}^{T o t}$ and $\pi_{N}$ denote the growth rates of $P, P_{T H}^{T o t}$, and $P_{N}$ respectively.

${ }^{a}$ All standard deviations are relative to output (GDP).

${ }^{b}$ Sectoral wages are the same as aggregate wages in both models.

Table 3: Variance decompositions

\begin{tabular}{lccccccccccc}
\hline \hline \multicolumn{1}{c}{ Variables: } & $n$ & $\frac{W}{P}$ & $C$ & $R N X$ & $T$ & $R E R$ & $e$ & $Y_{T H}^{T o t}$ & $Y_{N}$ & $n_{T H}$ & $n_{N}$ \\
\hline Shocks: & & & & & & & & & & \\
H money growth & 64.23 & 83.14 & 83.14 & 52.81 & 51.76 & 53.53 & 54.63 & 66.40 & 72.49 & 40.21 & 67.68 \\
F money growth & 6.10 & 0.50 & 0.50 & 33.54 & 32.23 & 34.85 & 36.31 & 12.03 & 2.4 & 7.72 & 3.01 \\
H tradeable technology & 12.92 & 0.91 & 0.91 & 1.11 & 2.03 & 0.34 & 0.23 & 11.84 & 1.19 & 36.65 & 1.47 \\
F tradeable technology & 8.79 & 4.93 & 4.93 & 6.29 & 7.98 & 4.52 & 3.72 & 4.07 & 8.12 & 11.56 & 5.09 \\
H nontradeable technology & 5.91 & 7.68 & 7.68 & 4.32 & 3.97 & 4.91 & 3.50 & 3.79 & 10.68 & 2.28 & 19.45 \\
F nontradeable technology & 0.45 & 0.33 & 0.33 & 0.39 & 0.54 & 0.25 & 0.22 & 0.29 & 0.39 & 0.59 & 0.29 \\
H government expenditure & 0.55 & 1.36 & 1.36 & 0.84 & 0.80 & 0.90 & 0.61 & 0.65 & 3.77 & 0.41 & 1.79 \\
F government expenditure & 1.06 & 1.15 & 1.15 & 0.70 & 0.70 & 0.69 & 0.77 & 0.92 & 0.96 & 0.57 & 1.24 \\
\hline \hline
\end{tabular}

NOTE: Shocks are orthogonalised using the Cholesky method, and the horizon is set at 200 quarters. Each column reports, for each variable, the share of the total variance explained by every shock, measured in per cent. The numbers are averages across all possible variance decompositions, given by the number of different orderings of the 8 shocks $(40,320)$. 
Table 4: LCP

\begin{tabular}{|c|c|c|c|c|c|c|c|c|c|c|}
\hline Standard deviations $^{a}$ & $n$ & $\frac{W}{P}$ & $C$ & $\pi$ & $N X$ & $R N X$ & $T$ & $R E R$ & $e$ & \\
\hline U.S. data & 1.41 & 4.08 & 0.77 & 0.33 & 0.33 & 0.28 & 1.77 & 4.86 & 4.78 & \\
\hline Infinite elasticity & 1.42 & 4.80 & 0.96 & 0.87 & 0.36 & 0.11 & 4.26 & 5.19 & 6.53 & \\
\hline Frisch $=1.5$ & 1.40 & 5.41 & 0.96 & 0.93 & 0.36 & 0.12 & 4.41 & 5.25 & 6.66 & \\
\hline Frisch $=0.75$ & 1.38 & 6.05 & 0.97 & 0.98 & 0.37 & 0.13 & 4.55 & 5.29 & 6.77 & \\
\hline Autocorrelations & $n$ & $\frac{W}{P}$ & $C$ & $\pi$ & $N X$ & $R N X$ & $T$ & $R E R$ & $e$ & \\
\hline U.S. data & 0.91 & 0.96 & 0.84 & 0.22 & 0.79 & 0.86 & 0.83 & 0.82 & 0.82 & \\
\hline Infinite elasticity & 0.66 & 0.65 & 0.65 & 0.64 & 0.65 & 0.79 & 0.56 & 0.65 & 0.71 & \\
\hline Frisch $=1.5$ & 0.65 & 0.65 & 0.65 & 0.64 & 0.64 & 0.79 & 0.57 & 0.64 & 0.71 & \\
\hline Frisch $=0.75$ & 0.64 & 0.65 & 0.65 & 0.63 & 0.64 & 0.80 & 0.58 & 0.64 & 0.71 & \\
\hline Cross-correlations & $n, Y$ & $\frac{W}{P}, Y$ & $C, Y$ & $\pi, Y$ & $N X, Y$ & $R N X, Y$ & $T, Y$ & $R E R, Y$ & $e, Y$ & \\
\hline U.S. data & 0.80 & 0.20 & 0.81 & 0.45 & -0.50 & -0.39 & 0.09 & 0.11 & 0.09 & \\
\hline Infinite elasticity & 0.56 & 0.99 & 0.99 & 0.97 & 0.77 & 0.14 & -0.68 & 0.77 & 0.71 & \\
\hline Frisch $=1.5$ & 0.53 & 0.97 & 0.99 & 0.95 & 0.76 & 0.09 & -0.68 & 0.77 & 0.69 & \\
\hline Frisch $=0.75$ & 0.50 & 0.94 & 0.98 & 0.94 & 0.76 & 0.07 & -0.66 & 0.77 & 0.67 & \\
\hline \multicolumn{11}{|c|}{ Sectoral standard deviations ${ }^{a}$} \\
\hline$\&$ cross-correlations & $Y_{T H}^{T o t}$ & $Y_{N}$ & $\pi_{T H}^{T o t}$ & $\pi_{N}$ & $n_{T H}$ & $n_{N}$ & $Y_{T H}^{T o t}, Y$ & $Y_{N}, Y$ & $n_{T H}, Y$ & $n_{N}, Y$ \\
\hline U.S. data & 1.99 & 0.40 & 0.66 & 0.35 & 1.57 & 0.71 & 0.90 & 0.49 & 0.82 & 0.74 \\
\hline Infinite elasticity $^{b}$ & 0.87 & 1.15 & 1.82 & 0.81 & 2.79 & 1.37 & 0.82 & 0.98 & 0.27 & 0.59 \\
\hline Frisch $=1.5^{b}$ & 0.89 & 1.15 & 1.90 & 0.87 & 2.82 & 1.36 & 0.80 & 0.98 & 0.24 & 0.56 \\
\hline Frisch $=0.75^{b}$ & 0.90 & 1.15 & 1.96 & 0.93 & 2.84 & 1.34 & 0.79 & 0.98 & 0.22 & 0.54 \\
\hline
\end{tabular}

NOTE: See Table 2. 
Table 5: PCP in exports and LCP in imports

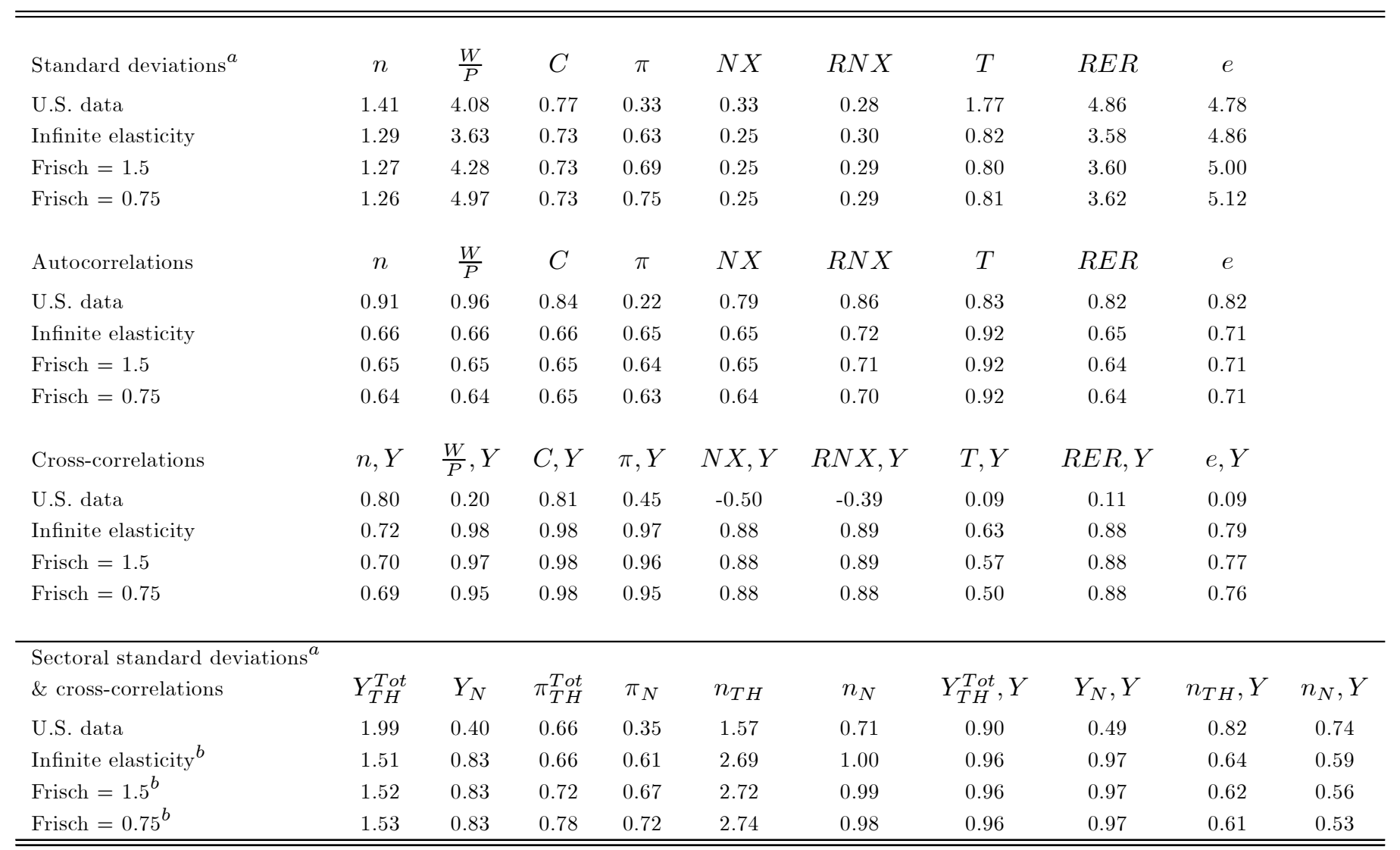

NOTE: See Table 2. 
Figure 1: Impulse responses of real net exports, terms of trade and real and nominal exchange rates to a $1 \%$ Home monetary shock
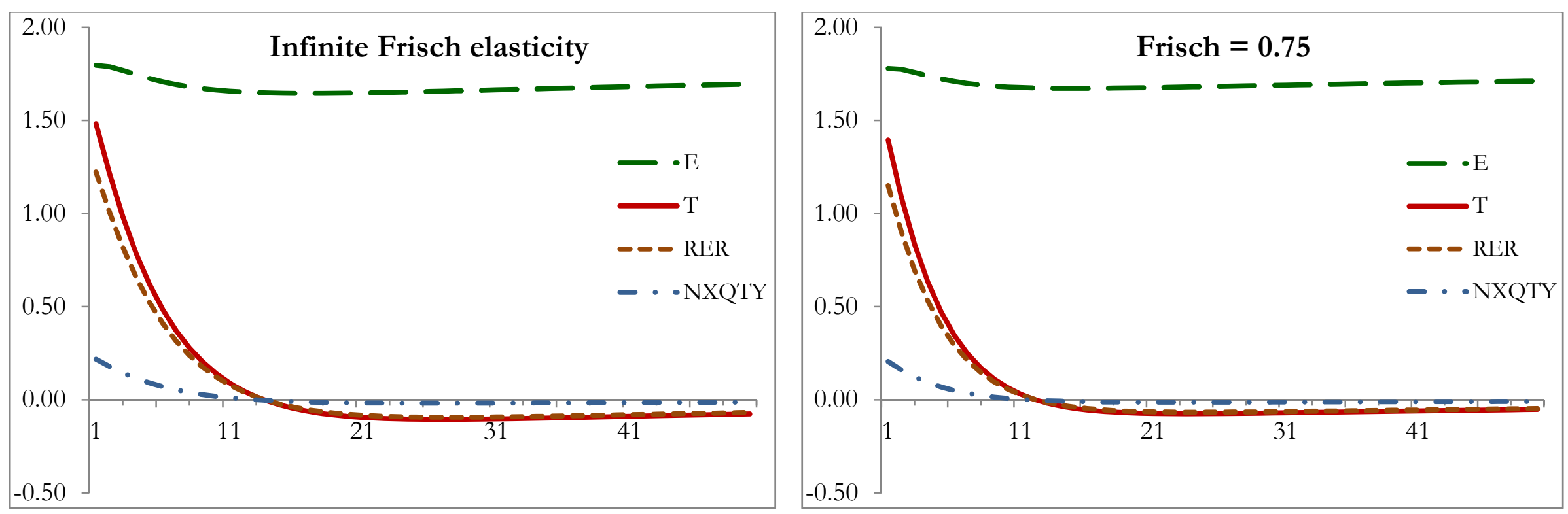

Note: Time is in quarters. 
Figure 2: Autocorrelations in the data and in the estimated models
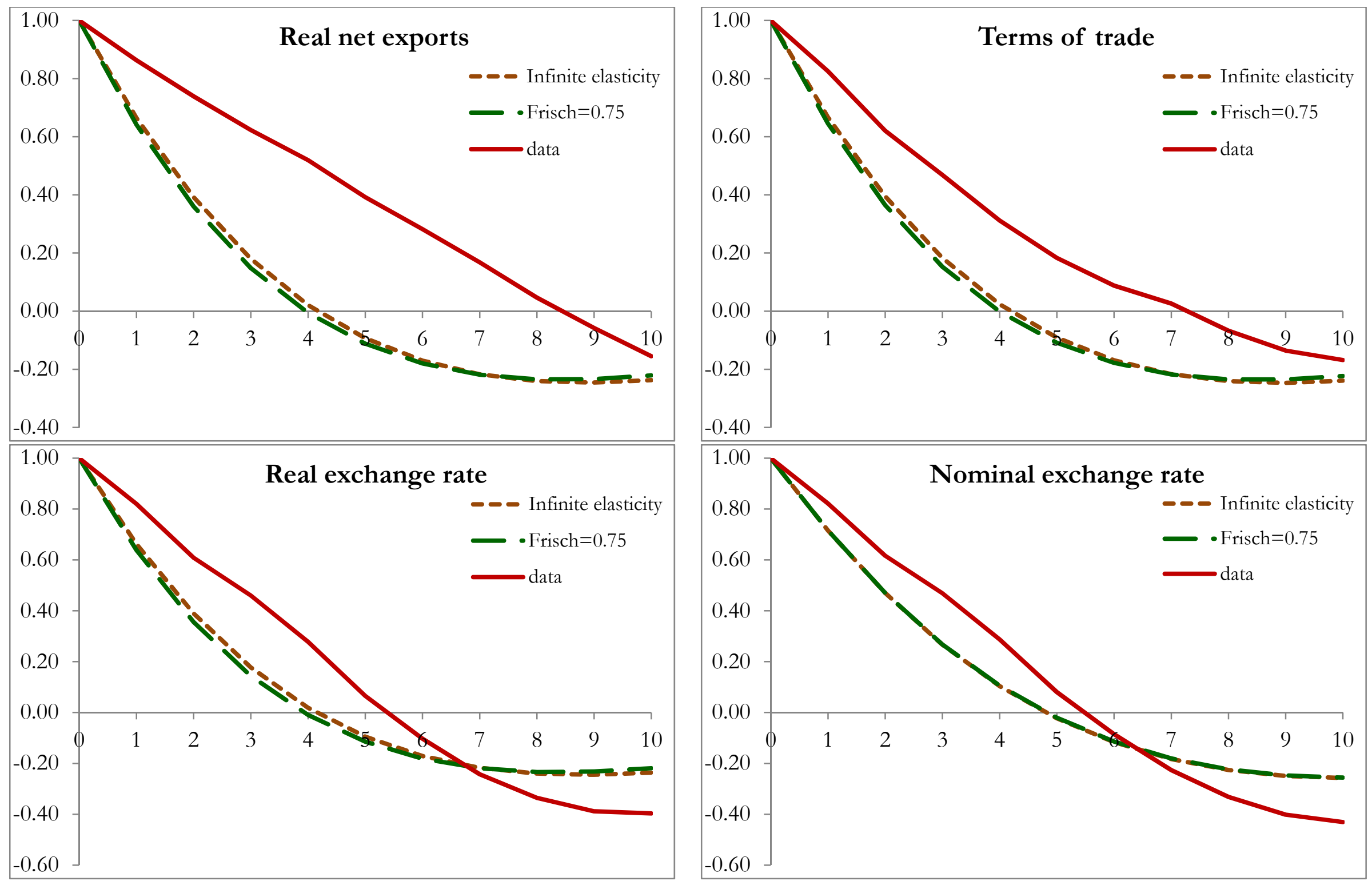

Note: Time is in quarters. 
Figure 3: Impulse responses of real net exports, terms of trade and real and nominal exchange rates to a 1\% Home tradeable technology shock
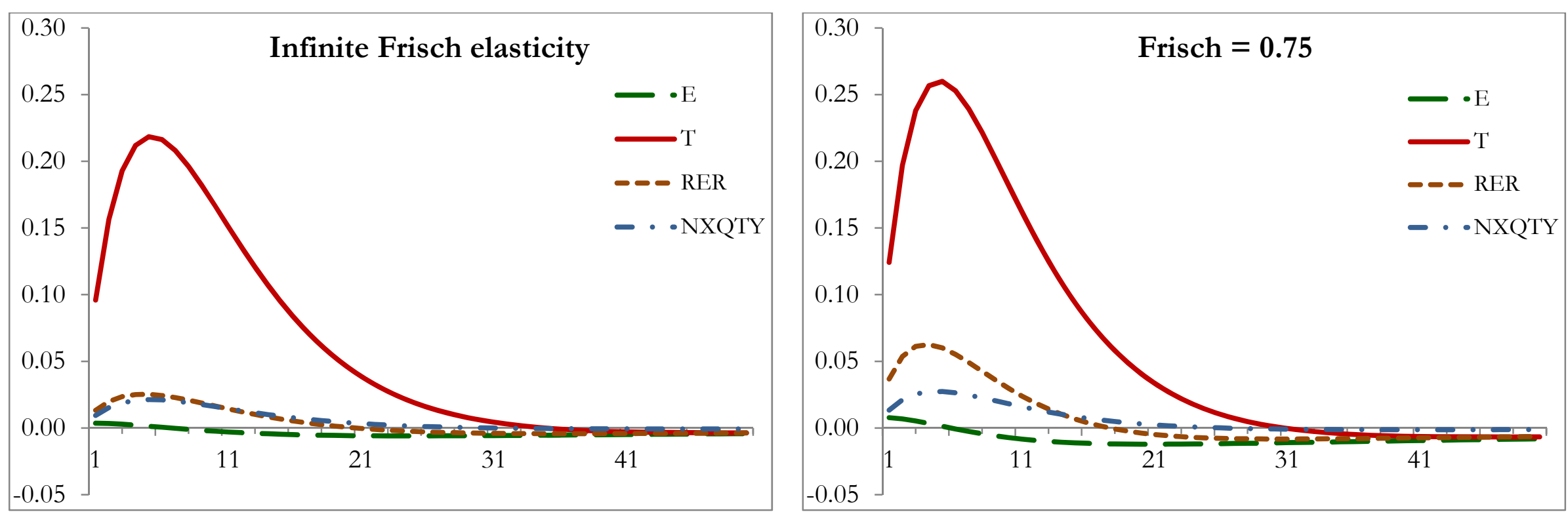

Note: Time is in quarters. 
Figure 4: Impulse responses of real net exports, terms of trade and real and nominal exchange rates to a 1\% Home nontradeable technology shock
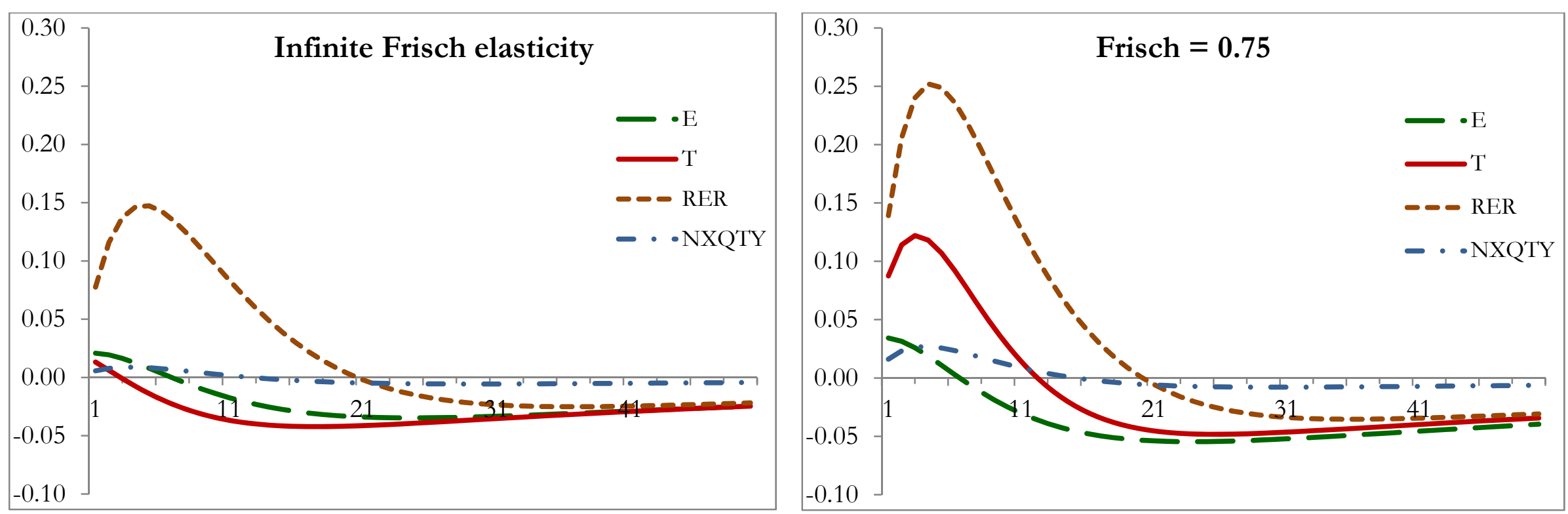

Note: Time is in quarters. 
Figure 5: Impulse responses of real net exports, terms of trade and real and nominal exchange rates to a $1 \%$ Home government expenditure shock.
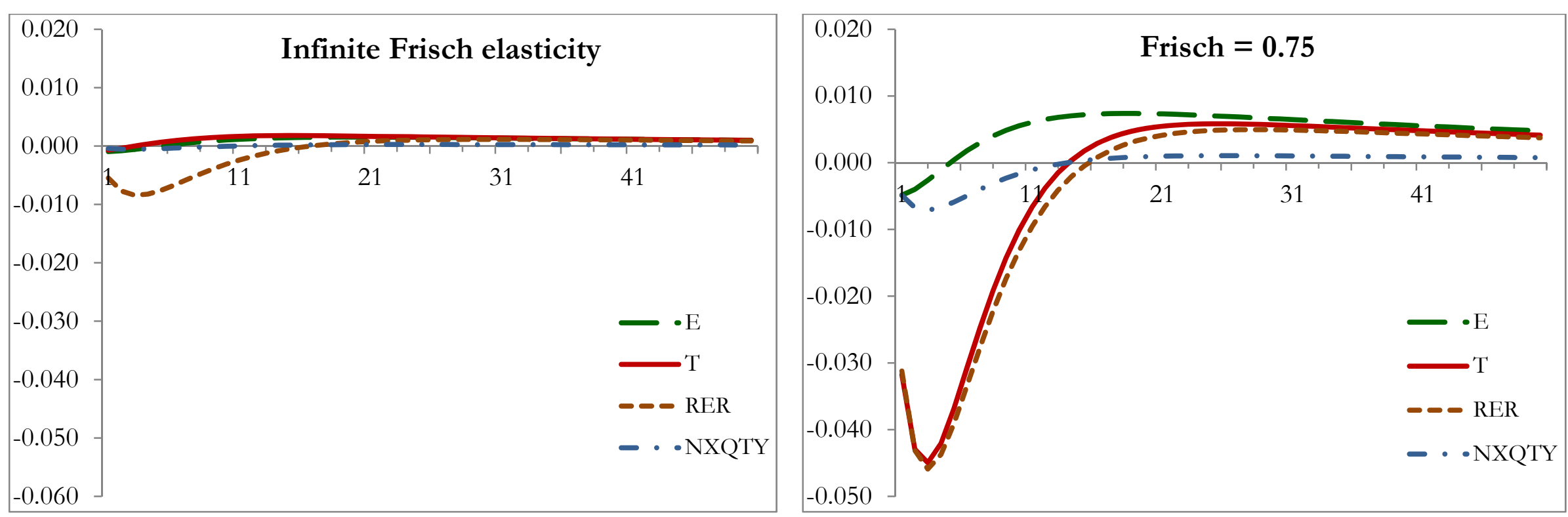

Note: Time is in quarters. 


\section{Appendices}

Appendices are included to facilitate the task of the referees but they are not intended for publication.

However, I will make them available on request.

\section{A.1 Data sources and calculations}

\begin{tabular}{lll}
\hline \hline Alias & Description & Source \\
& Dollar exchange rates & IMF IFS \\
& Exports of goods and services; Imports of goods and services & OECD QNA \\
& Exports deflator; Imports deflator & OECD QNA \\
$C$ & Private final consumption expenditure & OECD QNA \\
$e$ & Geometric GDP-weighted average of France, Germany, Canada, & \\
& Japan, Mexico and UK dollar exchange rates & \\
$n$ & Aggregate weekly hours index, total private industries & FRED \\
& (quarterly averages of monthly data) & \\
$n_{T H}$ & Employees in manufacturing & OECD MEI \\
$n_{N}$ & Employees of service-providing industries & BLS \\
& (quarterly averages of monthly data) & \\
$N X Q T Y$ & Exports - Imports of goods and services /GDP (chained volume estimates) \\
$N X$ & Exports - Imports of goods and services /GDP (current prices) & \\
$P$ & Consumer Price Index for all items & OECD MEI \\
$P^{*}$ & Geometric GDP-weighted average of Canada, France, Germany, & OECD MEI \\
& Japan, Mexico and UK CPI indexes & \\
$P_{T H}^{T o t}$ & Producer Price Index manufacturing industries & OECD MEI \\
$P_{N}$ & Consumer Price Index for services & BLS \\
$R E R$ & = eP* / P & \\
$T$ & Exports deflator / Imports deflator & \\
$W$ & Employment Cost Index, All workers & BLS \\
$W_{T H}$ & Employment Cost Index, Manufacturing & BLS \\
$W_{N}$ & Employment Cost Index, Service-producing industries & BLS \\
$Y$ & Gross Domestic Product & OECD QNA \\
$Y_{T H}^{T o t}$ & Index of production in total manufacturing & OECD MEI \\
$Y_{N}$ & Index of real Gross Domestic Product of services & BEA NIPA \\
\hline \hline & & \\
\hline
\end{tabular}




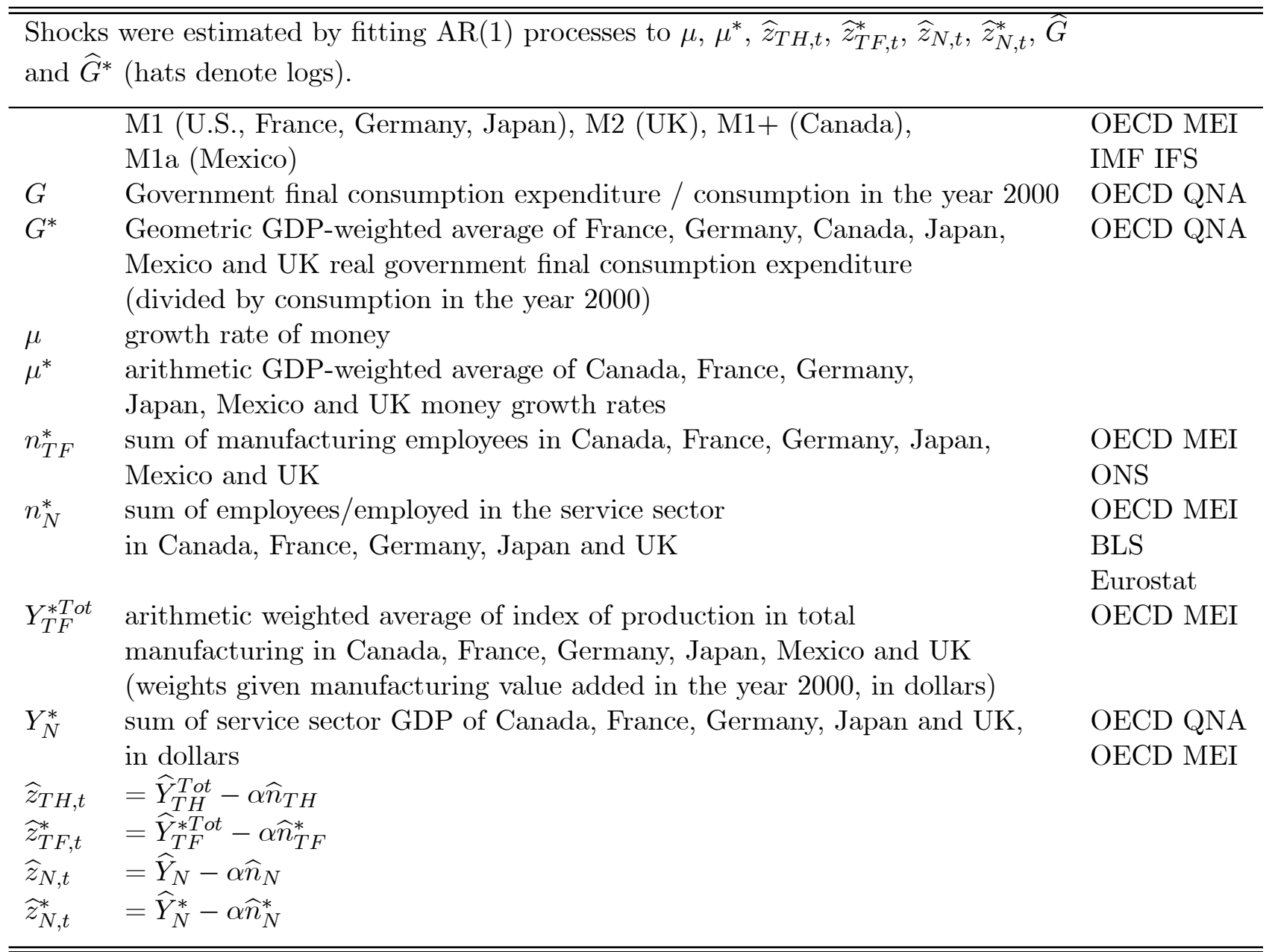

${ }^{a}$ Legend: BEA NIPA = Bureau of Economic Analysis, National Income and Product Accounts; BLS $=$ Bureau of Labor Statistics; FRED = Federal Reserve Economic Data;

IMF IFS = IMF International Financial Statistics; OECD MEI = OECD Main Economic Indicators; OECD QNA = OECD Quarterly National Accounts; ONS = Office for National Statistics, UK. 


\section{A.2 Nonconvexity, heterogeneity and labor supply elasticity}

In this Appendix I analyse whether the infinite labor supply elasticity in models with nonconvexities is due to employment lotteries, or the homogeneity of preferences. Do employment lotteries always result in an infinite labor supply elasticity? Or is the infinite elasticity due to the homogeneity of individuals' preferences? I will answer these questions first in the context of the indivisible labor model (i.e. when individuals are not able to adjust the number of hours worked), since the literature to date has focused on this type of nonconvexity. Then I will turn to the model presented in this paper, in which I assume that individuals can adjust the number of hours worked, but their commodity set is nonconvex because they cannot work in two sectors at the same time.

Some authors have shown that indivisible labor is not by itself a sufficient condition for the aggregate labor supply to have infinite elasticity. This point is made, for example, by Christiano, Trabandt and Walentin (2010), and is based on a model where individuals differ in their preference for leisure (or aversion to work). By assumption the economy is populated by a continuum of individuals, indexed with $i \in[0,1]$. The utility of individual $i$ is given by:

$$
\log \left(C_{t}\right)-i^{\nu}, \nu>0
$$

if employed, and by:

$$
\log \left(C_{t}\right)
$$

if unemployed.

Individuals are ranked according to their degree of aversion to work. Those with high $i$ have a strong aversion to work, and those with low $i$ have a low aversion to work. If $n_{t}$ is employment, then those with $0 \leq i \leq n_{t}$ work and those with $i>n_{t}$ do not. Individuals either work some fixed workweek or not at all. ${ }^{1}$ Everyone receives the same level of consumption. Aggregate utility is given by:

$$
\int_{0}^{1} \log \left(C_{t}\right) d i-\int_{0}^{n_{t}} i^{\nu} d i=\log \left(C_{t}\right)-\frac{n_{t}^{\nu+1}}{\nu+1} .
$$

\footnotetext{
${ }^{1}$ This assumption justifies why the amount of time spent at work does not affect the preference ordering.
} 
According to (3) the aggregate labor supply elasticity is equal to $1 / \nu$, hence it is possible to have a finite labor supply elasticity in an indivisible labor environment if individuals are heterogeneous. Moreover any finite aggregate labor supply elasticity can be calibrated by making an assumption on the cross-sectional distribution of skills or taste parameters.

However, Christiano, Trabandt and Walentin's (2010) result depends on a particular aggregation method, one which assumes that individuals are ranked according to their aversion to work, so that only those with low aversion go to work, while others never go to work (as long as $n_{t}<1$ ). One must find a justification for why individuals would spontaneously choose such arrangement, or alternatively, one could justify the aggregation of preferences (3) by means of a social planner. Christiano, Trabandt and Walentin (2010) assume instead a utilitarian household, which overrides individual choices like a de facto social planner. Therefore Equation (3) is the social planner or utilitarian household objective function, and the welfare-maximising equilibrium is the one in which only those individuals with a low aversion to work are employed. ${ }^{2}$

Aggregate outcomes are different in an equilibrium with lotteries. In this set-up $n_{t}(i)$ is the probability of being employed, and consistently with expected utility theory it enters the utility of individual $i$ linearly:

$$
\log \left[C_{t}(i)\right]-n_{t}(i) \cdot i^{\nu}
$$

The individual $i$ 's choice of employment lottery must satisfy the following first-order condition:

$$
\frac{1}{C_{t}(i)} \frac{W_{t}}{P_{t}}=i^{\nu}
$$

where $P_{t}$ is the aggregate price index, and $W_{t}$ is the market price of labor, assumed to be the same for all individuals. ${ }^{3}$ Let the aggregate labor supply be defined as:

$$
n_{t} \equiv \int_{0}^{1} n_{t}(i) d i
$$

\footnotetext{
${ }^{2}$ The social planner solution also emerges in an economy where the individuals commit to a risk-sharing arrangement. This solution concept is applied by Janko (2011), who assumes non-separability in consumption and leisure and homogeneous preferences.

${ }^{3}$ This assumption helps to simplify the analysis but is not crucial.
} 
Equations (5) and (6) imply that the aggregate labor supply elasticity is infinite. Therefore, heterogeneity per se does not guarantee a finite elasticity of labor supply, and much depends on how the aggregate variables are derived from the preferences of heterogeneous individuals. With indivisible labor and employment lotteries the elasticity of labor supply is infinite, even if agents are heterogeneous.

Notice that this result depends on the assumption that individuals know their type $i$ when they solve the maximisation problem, and the alternative assumption that individuals do not know their type would bring about a totally different result. In such alternative scenario, Equation (5) would hold in expectation and everyone would choose the same $C_{t}(i)$ and $n_{t}(i)$. Ex-post, after types are revealed, an individual who is allowed to re-optimise while keeping the same $C_{t}(i)$ would choose $n_{t}(i)=0$. Again in this scenario individuals would not choose an equilibrium in which only those with low $i$ work.

I now turn to the model of Section 2 to further investigate the relationship between nonconvexity and the labor supply elasticity. Here nonconvexity arises because individuals cannot work in two sectors at the same time. I modify the utility function by assuming that individuals are heterogeneous in their preference for leisure, in a way similar to Christiano, Trabandt and Walentin (2010), but I keep the same functional form as in Section 2. For the sake of simplicity, I consider a one-period economy with flexible prices but without money, government expenditure and bonds, but all the other assumptions remain unchanged.

The Home country is populated by a continuum of individuals $i \in(0,1]$ who differ in regard to their preference for leisure. The utility function of individual $i$ is given by:

$$
\begin{gathered}
\frac{C^{1-\sigma}-1}{1-\sigma}+v\left(\mathbf{h}_{T H}, \mathbf{h}_{N}, i\right), \\
v\left(\mathbf{h}_{T H}, \mathbf{h}_{N}, i\right)= \begin{cases}\frac{\kappa}{\omega}\left(1-\psi-\mathbf{h}_{T H}\right)^{\omega} i^{\nu} & \text { if } \mathbf{h}_{T H} \neq 0, \\
\frac{\kappa}{\omega}\left(1-\psi-\mathbf{h}_{N}\right)^{\omega} i^{\nu} & \text { if } \mathbf{h}_{N} \neq 0, \\
\frac{\kappa}{\omega}(\tau)^{\omega} i^{\nu} & \text { if } \mathbf{h}_{T H}=\mathbf{h}_{N}=0,\end{cases}
\end{gathered}
$$

with $\omega, \nu>0$. 


\section{The utilitarian household problem}

The household assigns a measure $n_{T H}$ of individuals to the tradeable goods sector and a measure $n_{N}$ to the nontradeable goods sector. Those employed in the tradeable goods sector supply $\mathbf{h}_{T H}$ hours and those employed in the nontradeable goods sector supply $\mathbf{h}_{N}$ hours of work. All individuals working in a sector work the same hours, however both $\mathbf{h}_{T H}$ and $\mathbf{h}_{N}$ are choice variables. As in Christiano, Trabandt and Walentin (2010) (and the literature on nonconvexity in labor supply) I assume that the household gives everyone the same level of consumption. ${ }^{4}$ I assume that profits from monopolistically competitive firms are distributed equally.

The utilitarian household allocates the individuals with the lowest $i$ to the sector with the longer workweek. For example, if $\tau \geq 1-\psi-\mathbf{h}_{N} \geq 1-\psi-\mathbf{h}_{T H}$ then the household's objective is to maximise:

$$
\begin{gathered}
\max \frac{C^{1-\sigma}-1}{1-\sigma}+\int_{0}^{n_{T H}} \frac{\kappa}{\omega}\left(1-\psi-\mathbf{h}_{T H}\right)^{\omega} i^{\nu} d i \\
+\int_{n_{T H}}^{n_{T H}+n_{N}} \frac{\kappa}{\omega}\left(1-\psi-\mathbf{h}_{N}\right)^{\omega} i^{\nu} d i+\int_{n_{T H}+n_{N}}^{1} \frac{\kappa}{\omega}(\tau)^{\omega} i^{\nu} d i
\end{gathered}
$$

subject to:

$$
P C \leq n_{T H} W_{T H} \mathbf{h}_{T H}+n_{N} W_{N} \mathbf{h}_{N}+\int_{0}^{1} \Pi_{T H}\left(f_{T H}\right) d f_{T H}+\int_{0}^{1} \Pi_{N}\left(f_{N}\right) d f_{N} .
$$

The first-order conditions with respect to hours and participation rates are:

$$
\begin{gathered}
\frac{\kappa}{\omega}\left(1-\psi-\mathbf{h}_{T H}\right)^{\omega} n_{T H}^{\nu}+\frac{\kappa}{\omega}\left(1-\psi-\mathbf{h}_{N}\right)^{\omega}\left(n_{T H}+n_{N}\right)^{\nu} \\
-\frac{\kappa}{\omega}\left(1-\psi-\mathbf{h}_{N}\right)^{\omega} n_{T H}^{\nu}-\frac{\kappa}{\omega}(\tau)^{\omega}\left(n_{T H}+n_{N}\right)^{\nu}=-\frac{C^{-\sigma}}{P} W_{T H} \mathbf{h}_{T H}, \\
\frac{\kappa}{\omega}\left(1-\psi-\mathbf{h}_{N}\right)^{\omega}\left(n_{T H}+n_{N}\right)^{\nu}-\frac{\kappa}{\omega}(\tau)^{\omega}\left(n_{T H}+n_{N}\right)^{\nu}=-\frac{C^{-\sigma}}{P} W_{N} \mathbf{h}_{N},
\end{gathered}
$$

\footnotetext{
${ }^{4}$ Thus the allocation of consumption is the same as in the equilibrium with lotteries which I will discuss later.
} 


$$
\begin{gathered}
\kappa\left(1-\psi-\mathbf{h}_{T H}\right)^{\omega-1} \frac{\left(n_{T H}\right)^{\nu+1}}{\nu+1}=-\frac{C^{-\sigma}}{P} n_{T H} W_{T H}, \\
\kappa\left(1-\psi-\mathbf{h}_{N}\right)^{\omega-1}\left[\frac{\left(n_{T H}+n_{N}\right)^{\nu+1}}{\nu+1}-\frac{\left(n_{T H}\right)^{\nu+1}}{\nu+1}\right]=-\frac{C^{-\sigma}}{P} n_{N} W_{N} .
\end{gathered}
$$

Equations (10) to (13) show that in the utilitarian household solution participation rates do not enter linearly the first-order conditions. Hence, it is possible to have a finite labor supply elasticity in the model if individuals are heterogeneous. The parameter $\nu$ can be used to calibrate the labor supply elasticity in a given parameterization.

\section{Equilibrium with lotteries and insurance market}

An individual chooses a probability $n_{T H}(i)$ of working in the tradeable sector and a probability $n_{N}(i)$ of working in the nontradeable sector. A lottery is held to determine which individuals must work and in which sector. Individuals are paid only for the work that they actually do, but have access to an insurance market. Because there are two sources of income risk, the risk of being unemployed and the risk of being allocated to the sector paying the lowest wage, one insurance contract is not enough to attain full insurance. Therefore I assume that individuals buy two policies with two separate insurance firms. Under policy 1 a premium is due if employed in sector $T H$, and under policy 2 a premium is due if employed in sector $N$. Both policies pay out a compensation in case of unemployment. I now show that this arrangement is sufficient to deliver full insurance.

The individual $i$ chooses the compensation levels $y_{1}(i)$ and $y_{2}(i)$ by solving the following problem:

$$
\begin{gathered}
\max \quad n_{T H}(i)\left[\frac{(C(i \mid T H))^{1-\sigma}-1}{1-\sigma}+\frac{\kappa}{\omega}\left(1-\psi-\mathbf{h}_{T H}(i)\right)^{\omega} i^{\nu}\right] \\
+n_{N}(i)\left[\frac{(C(i \mid N))^{1-\sigma}-1}{1-\sigma}+\frac{\kappa}{\omega}\left(1-\psi-\mathbf{h}_{N}(i)\right)^{\omega} i^{\nu}\right] \\
+\left(1-n_{T H}(i)-n_{N}(i)\right)\left[\frac{(C(i \mid U))^{1-\sigma}-1}{1-\sigma}+\frac{\kappa}{\omega}(\tau)^{\omega} i^{\nu}\right],
\end{gathered}
$$

subject to: 


$$
\begin{gathered}
P C(i \mid T H) \leq W_{T H} \mathbf{h}_{T H}(i)+\int_{0}^{1} \Pi_{T H}\left(f_{T H}\right) d f_{T H}+\int_{0}^{1} \Pi_{N}\left(f_{N}\right) d f_{N}-p_{1}(i) y_{1}(i), \\
P C(i \mid N) \leq W_{N} \mathbf{h}_{N}(i)+\int_{0}^{1} \Pi_{T H}\left(f_{T H}\right) d f_{T H}+\int_{0}^{1} \Pi_{N}\left(f_{N}\right) d f_{N}-p_{2}(i) y_{2}(i), \\
P C(i \mid U) \leq \int_{0}^{1} \Pi_{T H}\left(f_{T H}\right) d f_{T H}+\int_{0}^{1} \Pi_{N}\left(f_{N}\right) d f_{N}+y_{1}(i)+y_{2}(i),
\end{gathered}
$$

where $C(i \mid T H), C(i \mid N)$ and $C(i \mid U)$ are consumption of individual $i$ contingent on working in sectors $T H, N$ or being unemployed, and $p_{1}(i)$ and $p_{2}(i)$ are the two insurance prices.

The first-order conditions with respect to $y_{1}(i)$ and $y_{2}(i)$ are:

$$
\begin{gathered}
n_{T H}(i)(C(i \mid T H))^{-\sigma} p_{1}(i)=\left(1-n_{T H}(i)-n_{N}(i)\right)(C(i \mid U))^{-\sigma}, \\
n_{N}(i)(C(i \mid N))^{-\sigma} p_{2}(i)=\left(1-n_{T H}(i)-n_{N}(i)\right)(C(i \mid U))^{-\sigma} .
\end{gathered}
$$

Expected profits of both insurance firms are zero:

$$
\begin{aligned}
& n_{T H}(i) p_{1}(i) y_{1}(i)-\left(1-n_{T H}(i)-n_{N}(i)\right) y_{1}(i)=0, \\
& n_{N}(i) p_{2}(i) y_{2}(i)-\left(1-n_{T H}(i)-n_{N}(i)\right) y_{2}(i)=0,
\end{aligned}
$$

therefore:

$$
\begin{aligned}
& p_{1}(i)=\frac{1-n_{T H}(i)-n_{N}(i)}{n_{T H}(i)}, \\
& p_{2}(i)=\frac{1-n_{T H}(i)-n_{N}(i)}{n_{N}(i)} .
\end{aligned}
$$

Substituting (22) and (23) into the first-order conditions (18) and (19) we obtain: 


$$
\begin{gathered}
n_{T H}(i)(C(i \mid T H))^{-\sigma} \frac{1-n_{T H}(i)-n_{N}(i)}{n_{T H}(i)}=\left(1-n_{T H}(i)-n_{N}(i)\right)(C(i \mid U))^{-\sigma}, \\
n_{N}(i)(C(i \mid N))^{-\sigma} \frac{1-n_{T H}(i)-n_{N}(i)}{n_{N}(i)}=\left(1-n_{T H}(i)-n_{N}(i)\right)(C(i \mid U))^{-\sigma},
\end{gathered}
$$

which show that $C(i \mid T H)=C(i \mid N)=C(i \mid U)$. Therefore, the individual insures herself fully against income risk. Consumption of individual $i$, denoted by $C(i)$ from now on, is independent of the employment status. Moreover, since the left-hand sides of the constraints (15), (16) and (17) are identical, $y_{1}(i)$ and $y_{2}(i)$ are chosen so that the right-hand sides are identical too. This implies that income is equal to the expected wage given the lottery, regardless of the sector of employment:

$$
P C(i) \leq n_{T H}(i) W_{T H} \mathbf{h}_{T H}(i)+n_{N}(i) W_{N} \mathbf{h}_{N}(i)+\int_{0}^{1} \Pi_{T H}\left(f_{T H}\right) d f_{T H}+\int_{0}^{1} \Pi_{N}\left(f_{N}\right) d f_{N}
$$

The optimal choice of hours $\mathbf{h}_{T H}(i)$ and $\mathbf{h}_{N}(i)$, and probabilities $n_{T H}(i)$ and $n_{N}(i)$ satisfies the first-order conditions of the following problem:

$$
\begin{aligned}
& \max \frac{C(i)^{1-\sigma}-1}{1-\sigma}+n_{T H}(i) \frac{\kappa}{\omega}\left(1-\psi-\mathbf{h}_{T H}(i)\right)^{\omega} i^{\nu} \\
& +n_{N}(i) \frac{\kappa}{\omega}\left(1-\psi-\mathbf{h}_{N}(i)\right)^{\omega} i^{\nu}+\left(1-n_{T H}(i)-n_{N}(i)\right) \frac{\kappa}{\omega}(\tau)^{\omega} i^{\nu},
\end{aligned}
$$

subject to (26). These first-order conditions are:

$$
\begin{gathered}
C(i)^{-\sigma} \frac{W_{T H} \mathbf{h}_{T H}(i)}{P}+\frac{\kappa}{\omega}\left(1-\psi-\mathbf{h}_{T H}(i)\right)^{\omega} i^{\nu}-\frac{\kappa}{\omega}(\tau)^{\omega} i^{\nu}=0, \\
C(i)^{-\sigma} \frac{W_{N} \mathbf{h}_{N}(i)}{P}+\frac{\kappa}{\omega}\left(1-\psi-\mathbf{h}_{N}(i)\right)^{\omega} i^{\nu}-\frac{\kappa}{\omega}(\tau)^{\omega} i^{\nu}=0, \\
C(i)^{-\sigma} \frac{n_{T H}(i) W_{T H}}{P}-n_{T H}(i) \kappa\left(1-\psi-\mathbf{h}_{T H}(i)\right)^{\omega-1} i^{\nu}=0,
\end{gathered}
$$




$$
C(i)^{-\sigma} \frac{n_{N}(i) W_{N}}{P}-n_{N}(i) \kappa\left(1-\psi-\mathbf{h}_{N}(i)\right)^{\omega-1} i^{\nu}=0
$$

which in turn imply:

$$
\begin{gathered}
\frac{\kappa}{\omega}\left(1-\psi-\mathbf{h}_{T H}(i)\right)^{\omega}+\kappa\left(1-\psi-\mathbf{h}_{T H}(i)\right)^{\omega-1} \mathbf{h}_{T H}(i)=\frac{\kappa}{\omega}(\tau)^{\omega}, \\
\frac{\kappa}{\omega}\left(1-\psi-\mathbf{h}_{N}(i)\right)^{\omega}+\kappa\left(1-\psi-\mathbf{h}_{N}(i)\right)^{\omega-1} \mathbf{h}_{N}(i)=\frac{\kappa}{\omega}(\tau)^{\omega} .
\end{gathered}
$$

Therefore, $\mathbf{h}_{T H}(i)=\mathbf{h}_{N}(i) \equiv \mathbf{h}$ for all $i$, and $W_{T H}=W_{N} \equiv W$. Consequently the four first-order conditions reduce to just two:

$$
\begin{gathered}
C(i)^{-\sigma} \frac{W}{P} \mathbf{h}+\frac{\kappa}{\omega}(1-\psi-\mathbf{h})^{\omega} i^{\nu}-\frac{\kappa}{\omega}(\tau)^{\omega} i^{\nu}=0, \\
C(i)^{-\sigma} \frac{W}{P}-\kappa(1-\psi-\mathbf{h})^{\omega-1} i^{\nu}=0 .
\end{gathered}
$$

Equations (34) and (35) imply that optimal hours are the same for each individual and do not depend on $\frac{W}{P}$. However, heterogeneous individuals choose different probabilities, therefore the law of large numbers is not applicable.

Let us define $n(i) \equiv n_{T H}(i)+n_{N}(i)$ and $n \equiv \int_{0}^{1} n(i) d i$. It is easy to verify that the Frisch elasticity of aggregate labor supply:

$$
\frac{\vartheta(n \mathbf{h})}{\vartheta W / P} \frac{W / P}{n \mathbf{h}}=\frac{\vartheta n}{\vartheta W / P} \frac{W / P}{n}
$$

is infinite. Therefore, similarly to the indivisible labor model, individual heterogeneity in itself does not guarantee that the labor supply has finite elasticity. Whether or not this is the case depends on the choice of equilibrium and how the aggregate variables are derived from the preferences of heterogeneous individuals. 


\section{A.3 Two-sector open economy version of Hansen (1985) and Rogerson (1988a)}

The purpose of this Appendix is to show how the indivisible labor assumption of Hansen (1985) and Rogerson (1988a) can be applied to a two-sector open economy model, and to explain why the resulting labor supply is nonstandard.

Individuals can either work a fixed workweek $\mathbf{h}_{0}$, or not at all, but they can freely allocate their fixed workweek between the tradeable and nontradeable sectors. They choose a probability of being employed in each period $\left(n_{t}\right)$, and a lottery determines which individuals actually work. Using the same notation and functional forms of Section 2, the individual maximization problem can be written as follows:

$$
\max \quad U_{0}=E_{0} \sum_{t=0}^{\infty} \beta^{t}\left[\begin{array}{c}
\frac{C_{t}^{1-\sigma}-1}{1-\sigma}+\frac{\chi}{1-\varepsilon}\left(\frac{M_{t}}{P_{t}}\right)^{1-\varepsilon} \\
+n_{t} \cdot \frac{\kappa}{\omega}\left(1-\psi-\mathbf{h}_{T H, t}-\mathbf{h}_{N, t}\right)^{\omega}+\left(1-n_{t}\right) \cdot \frac{\kappa}{\omega}(\tau)^{\omega}
\end{array}\right],
$$

subject to

$$
\begin{gathered}
B_{t} P_{T, t}+\frac{\nu}{C_{0}} B_{t}^{2} P_{T, t}+M_{t} \leq\left(1+r_{t-1}\right) B_{t-1} P_{T, t}+M_{t-1} \\
\quad+T R_{t}-P_{t} C_{t}+n_{t} W_{t}\left(\mathbf{h}_{T H, t}+\mathbf{h}_{N, t}\right) \\
+\int_{0}^{1} \Pi_{T H, t}\left(f_{T H}\right) d f_{T H}+\int_{0}^{1} \Pi_{N, t}\left(f_{N}\right) d f_{N}+R_{t},
\end{gathered}
$$

$$
\mathbf{h}_{T H, t} \leq \mathbf{h}_{0}
$$

In an interior solution with $0<\mathbf{h}_{T H, t}<\mathbf{h}_{0}$ the optimal choice of $n_{t}$ and $\mathbf{h}_{T H, t}$ must satisfy the following first-order conditions:

$$
\begin{gathered}
\frac{\kappa}{\omega}\left(1-\psi-\mathbf{h}_{T H, t}-\mathbf{h}_{N, t}\right)^{\omega}+C_{t}^{-\sigma} \frac{W_{t}}{P_{t}}\left(\mathbf{h}_{T H, t}+\mathbf{h}_{N, t}\right)=\frac{\kappa}{\omega}(\tau)^{\omega}, \\
n_{t} \cdot \kappa\left(1-\psi-\mathbf{h}_{T H, t}-\mathbf{h}_{N, t}\right)^{\omega-1}=C_{t}^{-\sigma} n_{t} \frac{W_{t}}{P_{t}}
\end{gathered}
$$

while $\mathbf{h}_{N, t}$ is given by: 


$$
\mathbf{h}_{N, t}=\mathbf{h}_{0}-\mathbf{h}_{T H, t}
$$

The labor supply is completely described by Equations (36) to (38). Notice that it is not possible to solve for $n_{t}, \mathbf{h}_{T H, t}$ and $\mathbf{h}_{N, t}$. This becomes apparent after combining Equations (36) and (37) and simplifying the resulting expression:

$$
\left(1-\psi-\mathbf{h}_{T H, t}-\mathbf{h}_{N, t}\right)^{\omega}+\omega\left(1-\psi-\mathbf{h}_{T H, t}-\mathbf{h}_{N, t}\right)^{\omega-1}\left(\mathbf{h}_{T H, t}+\mathbf{h}_{N, t}\right)=(\tau)^{\omega} .
$$

Sectoral hours $\mathbf{h}_{T H, t}$ and $\mathbf{h}_{N, t}$ are not identified because they are perfect substitutes. Equation (39) does not provide sufficient information to solve for $\mathbf{h}_{T H, t}$ and $\mathbf{h}_{N, t}$, but it enables us to calibrate $\mathbf{h}_{0}$ using the preference parameters $\psi, \omega$ and $\tau$ :

$$
\left(1-\psi-\mathbf{h}_{0}\right)^{\omega}+\omega\left(1-\psi-\mathbf{h}_{0}\right)^{\omega-1} \mathbf{h}_{0}=(\tau)^{\omega}
$$

After log-linearizing Equations (36) to (38) we obtain:

$$
\begin{gathered}
\sigma \widehat{C}_{t}=\widehat{W}_{t}-\widehat{P}_{t}, \\
\frac{\omega-1}{1-\psi-\mathbf{h}_{0}} \mathbf{h}_{T H 0} \widehat{\mathbf{h}}_{T H, t}+\frac{\omega-1}{1-\psi-\mathbf{h}_{0}} \mathbf{h}_{N 0} \widehat{\mathbf{h}}_{N, t}-\sigma \widehat{C}_{t}+\left(\widehat{W}_{t}-\widehat{P}_{t}\right)=0, \\
\mathbf{h}_{T H 0} \widehat{\mathbf{h}}_{T H, t}+\mathbf{h}_{N 0} \widehat{\mathbf{h}}_{N, t}=0 .
\end{gathered}
$$

The log-linearized system above simplifies to just two equations:

$$
\begin{gathered}
\sigma \widehat{C}_{t}=\widehat{W}_{t}-\widehat{P}_{t}, \\
\mathbf{h}_{T H 0} \widehat{\mathbf{h}}_{T H, t}+\mathbf{h}_{N 0} \widehat{\mathbf{h}}_{N, t}=0 .
\end{gathered}
$$

Since $\frac{\vartheta\left(\widehat{W}_{t}-\widehat{P}_{t}\right)}{\vartheta \widehat{n}_{t}}=0$, the extensive labor supply elasticity $\frac{\vartheta n_{t}}{\vartheta \frac{W_{t}}{P_{t}}} \cdot \frac{\frac{W_{t}}{P_{t}}}{n_{t}}=\frac{\vartheta \widehat{n}_{t}}{\vartheta\left(\widehat{W}_{t}-\widehat{P}_{t}\right)}$ is infinite.

In the system (40) and (41) there is no functional relationship linking hours to the wage rate: 
sectoral hours are just a function of each other. As a result, both $\frac{\vartheta \widehat{\mathbf{h}}_{T H, t}}{\vartheta\left(\widehat{W}_{t}-\widehat{P}_{t}\right)}$ and $\frac{\vartheta \widehat{\mathbf{h}}_{N, t}}{\vartheta\left(\widehat{W}_{t}-\widehat{P}_{t}\right)}$ are not defined, hence it is not possible to compute the intensive labor supply elasticities $\frac{\vartheta \mathbf{h}_{T H, t}}{\vartheta \frac{W_{t}}{P_{t}}} \cdot \frac{\frac{W_{t}}{P_{t}}}{\mathbf{h}_{T H, t}}$ and $\frac{\vartheta \mathbf{h}_{N, t}}{\vartheta \frac{W_{t}}{P_{t}}} \cdot \frac{\frac{W_{t}}{P_{t}}}{\mathbf{h}_{N, t}}$.

The labor supply is nonstandard, in the sense that we can only identify the elasticity with respect to employment, but not with respect to hours worked in the two sectors.

The labor market equilibrium can be found by solving the supply and demand equations simultaneously. In the two-sector open economy version of Hansen and Rogerson the log-linearized labor demand equations are:

$$
\begin{gathered}
\widehat{n}_{t}+\widehat{\mathbf{h}}_{T H, t}=-\frac{1}{\alpha} \widehat{z}_{T H, t}+\frac{1}{\alpha} k_{1} \widehat{Y}_{T H, t}+\frac{1}{\alpha}\left(1-k_{1}\right) \widehat{Y}_{T H, t}^{*}, \\
\widehat{n}_{t}+\widehat{\mathbf{h}}_{N, t}=-\frac{1}{\alpha} \widehat{z}_{N, t}+\frac{1}{\alpha} \widehat{Y}_{N, t} .
\end{gathered}
$$

In the model in which labor cannot be supplied to both sectors simultaneously wages are equalized between sectors and hours worked are constant, therefore the labor supply equation is (40). The labor demand equations are:

$$
\begin{gathered}
\widehat{n}_{T H, t}=-\frac{1}{\alpha} \widehat{z}_{T H, t}+\frac{1}{\alpha} k_{1} \widehat{Y}_{T H, t}+\frac{1}{\alpha}\left(1-k_{1}\right) \widehat{Y}_{T H, t}^{*}, \\
\widehat{n}_{N, t}=-\frac{1}{\alpha} \widehat{z}_{N, t}+\frac{1}{\alpha} \widehat{Y}_{N, t} .
\end{gathered}
$$

In the two-sector open economy version of Hansen and Rogerson the labor market equilibrium is the solution to the simultaneous equations system (42), (43), (40) and (41), whereas in the model in which labor cannot be supplied to both sectors simultaneously the labor market equilibrium is the solution to (44), (45) and (40). Therefore, the two models have the same log-linearized solution: in the two-sector open economy version of Hansen and Rogerson aggregate hours worked in the two sectors are measured by $n_{t} \mathbf{h}_{T H, t}$ and $n_{t} \mathbf{h}_{N, t}$, and in the model in which labor cannot be supplied to both sectors simultaneously they are measured by $n_{T H, t}$ and $n_{N, t}$. 
Recent UWE Economics Papers

See http://www1.uwe.ac.uk/bl/research/bristoleconomicanalysis for a full list.

1312 Modelling the sectoral allocation of labour in open economy models Laura Povoledo

1311 The US Fed and the Bank of England: ownership, structure and 'independence' Peter Howells

1310 Cross-hauling and regional input-output tables: the case of the province of Hubei, China Anthony T. Flegg, Yongming Huang and Timo Tohmo

1309 Temporary employment, job satisfaction and subjective well-being Chris Dawson and Michail Veliziotis

1308 Risk taking and monetary policy before the crisis: the case of Germany Iris Biefang-Frisancho Mariscal

1307 What determines students' choices of elective modules? Mary R Hedges, Gail A Pacheco and Don J Webber

1306 How should economics curricula be evaluated? Andrew Mearman

1305 Temporary employment and wellbeing: Selection or causal? Chris Dawson, Don J Webber and Ben Hopkins

1304 Trade unions and unpaid overtime in Britain Michail Veliziotis

1303 Why do students study economics?

Andrew Mearman, Aspasia Papa and Don J. Webber

1302 Estimating regional input coefficients and multipliers: The use of the FLQ is not a gamble Anthony T. Flegg and Timo Tohmo

1301 Liquidity and credit risks in the UK's financial crisis: How QE changed the relationship Woon Wong, Iris Biefang-Frisancho Mariscal, Wanru Yao and Peter Howells

1221 The impact of the quality of the work environment on employees' intention to quit Ray Markey, Katherine Ravenswood and Don J. Webber

1220 The changing influence of culture on job satisfaction across Europe: 1981-2008

Gail Pacheco, De Wet van der Westhuizen and Don J. Webber

1219 Understanding student attendance in Business Schools: an exploratory study Andrew Mearman, Don J. Webber, Artjoms Ivḷevs, Tanzila Rahman \& Gail Pacheco

1218 What is a manufacturing job?

Felix Ritchie, Andrew D. Thomas and Richard Welpton

1217 Rethinking economics: Logical gaps - empirical to the real world Stuart Birks 
1216 Rethinking economics: Logical gaps - theory to empirical Stuart Birks

1215 Rethinking economics: Economics as a toolkit Stuart Birks

1214 Rethinking economics: Downs with traction Stuart Birks

1213 Rethinking economics: theory as rhetoric Stuart Birks

1212 An economics angle on the law Stuart Birks

1211 Temporary versus permanent employment: Does health matter? Gail Pacheco, Dominic Page and Don J. Webber

1210 Issues in the measurement of low pay: 2010 Suzanne Fry and Felix Ritchie

1209 Output-based disclosure control for regressions Felix Ritchie

1208 Sample selection and bribing behaviour Timothy Hinks and Artjoms Ivḷevs

1207 Internet shopping and Internet banking in sequence Athanasios G. Patsiotis, Tim Hughes and Don J. Webber

1206 Mental and physical health: Reconceptualising the relationship with employment propensity Gail Pacheco, Dom Page and Don J. Webber

1205 Using student evaluations to improve individual and department teaching qualities Mary R. Hedges and Don J. Webber

1204 The effects of the 2004 Minority Education Reform on pupils' performance in Latvia Artjoms Ivḷevs and Roswitha M. King

1203 Pluralist economics curricula: Do they work and how would we know? Andrew Mearman

1202 Fractionalization and well-being: Evidence from a new South African data set Timothy Hinks

1201 The role of structural change in European regional productivity growth Eoin O'Leary and Don J. Webber

1112 Trusting neighbours or strangers in a racially divided society: Insights from survey data in South Africa

Dorrit Posel and Tim Hinks

1111 A comment on Tobias Kronenberg's "Construction of regional input-output tables using nonsurvey methods: The role of cross-hauling"

Anthony T. Flegg and Timo Tohmo 